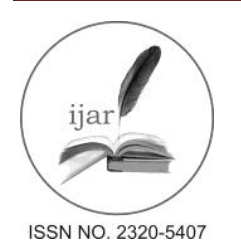

Journal homepage: http://www.journalijar.com

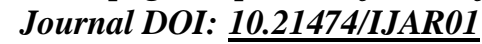

INTERNATIONAL JOURNAL

OF ADVANCED RESEARCH

RESEARCH ARTICLE

\title{
IMPACT OF SDR FLUCTUATIONS ON INCYLINDER FLOWS BY VARYING PISTON BOWL CONFIGARATIONS.
}

\author{
Dr. S M Jameel Basha ${ }^{1}$, Dr. G Naga Malleshwar Rao ${ }^{2}$, Dr. R Ramachandra ${ }^{3}$, Dr. P Issac Prasad ${ }^{4}$. \\ 1. Professor, Srinivasa Ramanujan Institute of Technology, Anantapur, Andhra Pradesh, India. \\ 2. Principal, Gates Institute of Technology, Gooty, Anantapur District, Andhra Pradesh, India. \\ 3. Principal, SKD Engineering College, Gooty, Anantapur District, Andhra Pradesh, India. \\ 4. Principal, Ramachandra College of Engineering, Eluru, Andhra Pradesh, India.
}

\section{Manuscript Info}

\section{Manuscript History:}

Received: 18 March 2016

Final Accepted: 22 April 2016

Published Online: May 2016

Key words:

SDRF, CFD, Flamelet equation,

*Corresponding Author

Dr. S M Jameel Basha.

\begin{abstract}
It is known fact that the CI engine combustion process is extremely complex. By modeling the In-cylinder processes by suitable combination of assumptions and equations we can analyze the critical features. The CFD models gives us complete understanding of the process under study from formulating the model, controlling the key variables giving rise to cost reduced and time consuming experimental methods. The CFD code used in the present work is FLUENT. FLUENT is very much useful in modeling Incylinder flows and gives better analysis of pollutants. All the codes run with their own assumptions and restrictions. In this code, it is found that the scalar dissipation rate fluctuations (SDRF) has been ignored which may cause inconsistency in the results. Hence this work is proposed to account SDRF and possible inclusion in the existing code. Three piston bowl configurations spherical, Mexican hat bowl (MHB) and Mexican hat bowl with lip (MHB with Lip) is considered in the present work. The results were presented in the form of graphs with and without considering the effect of SDRF. The validation of the results is done by comparing with the available experimental data.
\end{abstract}

\section{Introduction:-}

The liquid fuel, usually injected at high velocity as one or more jets through small orifices or nozzles in the injector tip, atomizes into small drops and penetrates into the combustion chamber. The fuel vaporizes and mixes with the high temperature, high pressure cylinder air. Since the air temperature and pressure are above the fuel's ignition point, spontaneous ignition of portions of the already mixed fuel and air occur after a delay period.

Because of the complication in the modeling of the ignition and combustion process in the DI engine it is not yet possible to model all these phenomena in a comprehensive manner. Modeling a process has come to mean developing and using appropriate combinations of assumptions and equations that permit critical features of the process to be analyzed. The modeling of engine processes continues to develop as our basic understanding of the physics and chemistry of the phenomena of interest steadily expands and as the capability of computers to solve complex equations continues to increase [1].

\section{Problem Definition:-}

Fairly good amount of works are reported on multidimentional modeling and the available information pertaining to in-cylinder processes is also abundant. The results predicted by modeling are some times proved to be consistent and sometimes to be inconsistent. The inconsistency in results is attributed to various assumptions in the codes. In 
this work, one such assumption Scalar Dissipation Rate Fluctuation (SDRF) was ignored. It is proposed to come out with the possible inclusion of SDRF in modeling. The code used for the present work is FLUENT. It has greater flexibility to write User Defined Functions (UDF) and append it to the existing code for different applications. Computations were carried out with SDRF and without SDRF and compared with the existing experimental data for three bowl configurations at injection timing of $28^{0}$ bTDC, injection duration of $23.5^{\circ}$ and the swirl ratio of 2 . The bowl configuration considered for analyses are 1.Hemispherical Bowl (HSB) 2.Mexican Hat Bowl with Lip (MHB with Lip) 3.Mexican Hat Bowl (MHB).

\section{Theory of computation:-}

The irregular nature of turbulence stands in contrast to laminar motion, because the fluid is imagined to flow in smooth laminate or layers. Virtually all flows of engineering interest are turbulent flows always occur when the Reynold's number is large[2]. Careful analysis of solutions to the Navier Strokes equation, or more typically to its boundary-layer form, shows that turbulence develops as instability in laminar flows. In principle the time-dependent, three dimensional Navier Strokes equation contains all of the physics of a given turbulent flow. This is true from the fact that turbulence is a continuum phenomenon[3] Even the smallest scales occurring in a turbulent flow are ordinarily for larger than any molecular length scale. Turbulent diffusion greatly enhances the transfer of mass, momentum and energy. Apparent stresses often develop in turbulent flows that are several orders of magnitude larger than in corresponding laminar flows [4-6].

Combustion essentially takes place in the vicinity of the surface of stoichiometric mixture[7]. Let us consider locally a co ordinate system where the co ordinates $\mathrm{x}_{2}$ and $\mathrm{x}_{3}$ are within that surface and the co ordinate $\mathrm{x}_{1}$ is normal to it. Now replace $\mathrm{x}_{1}$ by $\mathrm{Z}$ and retain the previous independent coordinates $\mathrm{x}_{2}$ and $\mathrm{x}_{3}$ and $\mathrm{t}$. This leads to temperature equation in the form of

$$
\rho\left(\frac{\partial T}{\partial t}+\sum_{k=2}^{3} v_{k} \frac{\partial T}{\partial x_{k}}\right)=\rho \frac{x}{2} \frac{\partial^{2} T}{\partial Z^{2}}+\sum_{k=2}^{3} \frac{\partial}{\partial x_{k}}\left(\rho D \frac{\partial T}{\partial x_{k}}\right)+\frac{1}{c p} \frac{\partial P}{\partial t}-\frac{1}{c p} \sum_{i=1}^{N} h_{i} m_{i}+2 \rho D \sum_{k=2}^{3} \frac{\partial Z}{\partial x_{k}} \frac{\partial^{2} T}{\partial Z \partial x_{k}}-\frac{1}{c p} \frac{\partial f_{k}}{\partial x_{k}}
$$

This equation contains scalar dissipation rate $\mathrm{X}$, defined as

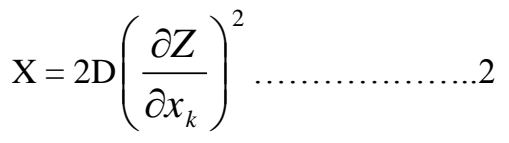

If the flamelet is thin in the $\mathrm{Z}$ direction an order of magnitude analysis similar to that for a boundary layer shows that the second derivative with respect to $\mathrm{Z}$ is a dominating term on the R.H.S of equation 1 . To lead the order in an asymptotic analysis this term must balance the reaction term on the right hand side. The term containing the time derivative is only important if very rapid changes such as extinction, occurs[8]. If the time derivative term is retained, the flamelet structure is to leading order described by the one dimensional time dependent temperature equation.

$$
\begin{aligned}
& \rho \frac{\partial T}{\partial t}=\rho \frac{X}{2} \frac{\partial^{2} T}{\partial Z^{2}}-\frac{1}{c p} \sum_{i=1}^{N} h_{i} m_{i}+\frac{1}{c p} \frac{\partial P}{\partial t}-\frac{1}{c p} \frac{\partial T_{k}}{\partial X_{k}} \ldots \ldots \ldots \ldots \ldots \ldots . \ldots . \ldots \\
& \rho \frac{\partial y_{i}}{\partial t}=\frac{1}{2} \rho \frac{\partial^{2} y_{i}}{\partial Z^{2}}+\omega_{i} \ldots \ldots \ldots \ldots \ldots \ldots . . .4
\end{aligned}
$$

Effects of turbulent flow are parameterized and imposed in the flamelet by the instantaneous scalar dissipation rate. It has the dimension $\sec ^{-1}$ and may be interpreted as the inverse of characteristic diffusion time. Due to the transformation it implicitly incorporates the influence of convection and diffusion normal to the surface of stoichiometric mixture. In the limit of $X=0.0$ the chemical source term $\left(\omega_{\mathrm{i}}\right)$ must sum to zero if transient and radiation loss terms are neglected. 
For the counter flow geometry, the scalar dissipation rate at the location where the mixture is stoichiometric may be approximated assuming constant density and diffusivity by

$\mathrm{X}_{\mathrm{st}}=4 \mathrm{a} Z_{s t}^{2}\left[\operatorname{erfc}^{-1}\left(2 Z_{\mathrm{st}}\right)\right]^{2} \ldots \ldots \ldots \ldots . .5$

Where ' $a$ ' is the velocity gradient and erfc ${ }^{-1}$ the inverse of complementary error function.

Equation 3 has been written with a scalar dissipation that varies with $\mathrm{Z}$ and possibly time. It also contains the unsteady term. First order terms in equation 3 that have been neglected are the convection term and the last but one term on the R.H.S which represents curvature effects. The second term on the R.H.S describes diffusion along lines of constant mixture fraction and comes in at second order only.

The scalar dissipation rate can be expanded around $\mathrm{Z}_{\mathrm{st}}$ as

$$
X=X_{s t}+\left(\frac{\partial X}{\partial Z}\right)_{Z_{s t}}\left(Z-Z_{s t}\right) \quad \ldots \ldots \ldots \ldots . . .6
$$

Since $\mathrm{Z}-\mathrm{Z}_{\mathrm{st}}$ in small in the reaction zone this expansion introduces a first order term with an additional parameter.

$\left(\frac{\partial X}{\partial Z}\right)_{s t}$. This term is not small and its fluctuations in a turbulent flow should be considered. Unsteady effects have

been analyzed by in a lagrangian simulation of flamelet extinction and re-ignition by solving the unsteady flamelet equations with a spatially constant but time- varying value of $X_{\text {st }}$.

Introducing these definitions into the flamelet eqns

$$
\begin{aligned}
& \frac{\partial y_{F}}{\partial \tau}-\frac{a x}{2} \frac{\partial^{2} y_{F}}{\partial Z^{2}}+\frac{1}{[1+v]} \omega=0.0 \ldots \ldots \ldots \ldots . . .7 \\
& \frac{\partial y_{0}}{\partial \tau}-\frac{a x}{2} \frac{\partial y_{0}}{\partial Z^{2}}+\left(\frac{v}{1+v}\right) \omega=0.0 \ldots \ldots \ldots \ldots . .8 \\
& \frac{\partial y_{P}}{\partial \tau}-\frac{a x}{2} \frac{\partial^{2} y_{P}}{\partial Z^{2}}-\omega=0.0 \ldots \ldots \ldots \ldots \ldots \ldots . . .9 \\
& \frac{\partial \theta}{\partial \tau}-\frac{a x}{2} \frac{\partial^{2} \theta}{\partial Z^{2}}-\omega=0.0 \ldots \ldots \ldots \ldots \ldots \ldots \ldots . . . \ldots \ldots \ldots
\end{aligned}
$$

Where the non-dimensional chemical source term is given by

$\omega=D_{a} \frac{(1+v)^{2}(1-\alpha) \exp \left(\beta_{r e f}-\beta\right)}{1-\alpha(1-\theta)} y_{F} y_{0} \exp \left(-\frac{Z_{e}(1-\theta)}{1-\alpha(1-\theta)}\right) \ldots \ldots \ldots \ldots . .11$

The diffusion term evaluated at stoichiometric conditions can be written using Taylor series of approximation.

$$
\frac{\partial^{2} T}{\partial Z^{2}} \approx-\frac{\left(T_{s t, b}-T_{s t, u}\right)}{\Delta Z Z_{s t}\left(1-Z_{s t}\right)} \theta_{s t} \ldots \ldots \ldots \ldots . . .12
$$

Substituting above values in equation 9 


$$
\frac{d \theta_{s t}}{d \tau}+x(\tau) \theta_{s t}-\omega\left(\theta_{s t}\right)=0.0 \ldots \ldots \ldots . .13
$$

with

$\omega=\frac{D_{a}(1-\alpha) \exp \left(\beta_{r e f}-\beta\right)}{1-\alpha\left(1-\theta_{s t}\right)}\left(1-\theta_{s t}\right)^{2} \exp \left(-\frac{Z_{e}\left(1-\theta_{s t}\right)}{1-\alpha\left(1-\theta_{s t}\right)}\right) \ldots \ldots \ldots \ldots \ldots \ldots . \ldots 14$

The above equation analyzes how random fluctuations of the scalar dissipation rate can influence the non-premixed combustion process.

\section{Test Computations:-}

These computations pertain to the test engine fitted with hemi-spherical bowl-in-piston. Fig 4.1 shows the view of typical mesh which represents the in-cylinder flow field. The computed pressure histories considering the effect of SDRF and ignoring SDRF is compared with the available measured pressure histories.

Figures 4.2 and 4.3 give the two front views of the computational meshes for these piston bowl configurations. The bowl volume remains the same for all the three cases considered.

\section{Comparison of predicted and experimental pressure histories:-}

Figure 4.4 gives the comparison of the predicted and experimental pressure histories. A good agreement is obtained during compression. The predicted pressures are slightly higher during the combustion and the small deviation between the two goes hand in hand during the later part of expansion stroke. In the normal engine operation, the incylinder charge prior to the combustion contains some portion of residual gases which could not be exhausted completely in the previous cycle. But only pure air without any residual gas is assumed to be compressed, in the present modeling. Hence higher predicted combustion pressures are resulted. The predicted peak pressures without SDRF, experimental [9] and with SDRF are 7.147 MPa, 6.829 MPa and 7.01Mpa respectively. The percentage error in the predicted peak pressure without SDRF and experimental value is $4.449 \%$ and the percentage error in the predicted peak pressure with SDRF and experimental value is $2.58 \%$.

Figure 4.5 gives the comparison of the predicted and experimental pressure histories for MHB. The value of peak pressure without considering the effect of SDRF is $6.977 \mathrm{MPa}$, considering the effect of SDRF is $6.563 \mathrm{MPa}$ and experimental [9] peak pressure is 6.387 MPa. The percentage error in the predicted peak pressure without SDRF and experimental value is $5.91 \%$ and the percentage error in the predicted peak pressure with SDRF and experimental value is $4 \%$. Figure 4.6 gives the comparison of the predicted and experimental pressure histories for MHB with Lip. The value of peak pressure without considering the effect of SDRF is $7.423 \mathrm{MPa}$, considering the effect of SDRF is 7.248 MPa and experimental peak pressure is 7.115 MPa. The percentage error in the predicted peak pressure without SDRF and experimental value is 3.1\% and the percentage error in the predicted peak pressure with SDRF and experimental value is $1.83 \%$.

\section{Effect of piston bowl configuration on in-cylinder pressure:-}

Figure $4.7\left(\mathrm{a}_{1}\right), 4.7\left(\mathrm{a}_{2}\right)$ and $4.7\left(\mathrm{a}_{3}\right)$ gives the comparison of predicted pressure histories for different bowl configurations with and without considering the effect of SDRF. Rise in pressure in the entire three piston bowls are more are less the same. Early pressure raise due to combustion is seen in MHB as compared to MHB with lip but as the crank angle proceeds to TDC the peak pressure is noticed in MHB with lip. The HSB falls in between the two. The peak pressure in MHB with lip and HSB are 7.29 Mpa and 7.147Mpa. The peak pressure is lower in case of MHB equal to 6.977 Mpa. The peak pressures in MHB with lip and HSB considering the effect of SDRF are 7.145 $\mathrm{Mpa}$ and 7.01 MPa. The peak pressure in case of MHB is equal to $6.837 \mathrm{MPa}$. Reduced peak pressures are noticed when the effect of SDRF is considered.

\section{Effect of piston bowl configuration on in-cylinder temperature:-}

Figure 4.8 $\left(\mathrm{a}_{1}\right), 4.8\left(\mathrm{a}_{2}\right)$ and $4.8\left(\mathrm{a}_{3}\right)$ gives the comparison of variation of temperature with crank angle for the three bowl configurations. Raise in temperature is more pronounced in case of MHB with lip. The peak value of temperature in this case is $2699.98 \mathrm{k}$. The peak temperature is lower in case of $\mathrm{MHB}$, its value being equal to $2590.11 \mathrm{k}$. The HSB falls between these two with the value of peak temperature as $2658.55 \mathrm{k}$. However, it is known 
that the greater raise in temperatures in the cylinder gives raise to the formation of $\mathrm{NO}_{\mathrm{x}}$. By considering the effect of SDRF the peak value of temperature in case of MHB with lip is $2594.73 \mathrm{k}$. The peak temperature in case of MHB is equal to $2538.3 \mathrm{k}$. The peak value of temperature in case of HSB is $2613.7 \mathrm{k}$. When the effect of SDRF is accounted, the heat losses (which are a function of temperature) are observed. A probability density function considered in SDRF takes into account the adiabatic heat losses of the cylinder [10]. Hence, reduced temperatures considering SDRF are noticed.

\section{Effect of piston bowl configuration on total energy:-}

Figure 4.9( $\left.\mathrm{a}_{1}\right), 4.9\left(\mathrm{a}_{2}\right)$ and $4.9\left(\mathrm{a}_{3}\right)$ gives the comparison of variation of total energy with crank angle for the three bowl configurations. The heat release rate is greater in MHB with lip which confirms the trend of pressure raise in Fig 4.6. The peak total energy in case of MHB with lip is $496 \mathrm{KJ}$ where as in case of MHB and HSB it is equal to $434.25 \mathrm{KJ}$ and $439 \mathrm{KJ}$ respectively. By accounting SDRF the peak total energy in case of MHB with lip is 452.89 $\mathrm{KJ}$ where as in case of MHB and HSB it is equal to $442 \mathrm{KJ}$ and $444.25 \mathrm{KJ}$ respectively.

\section{Effect of piston bowl configuration on turbulent kinetic energy :-}

Figure 4.10 $\left(a_{1}\right), 4.10\left(a_{2}\right)$ and 4.10( $\left.a_{3}\right)$ gives the comparison of variation of TKE with crank angle for the three bowl configurations. The peak values of TKE in HSB, MHB and MHB with lip are 93.96, 46.06 and $84.38 \mathrm{~m}^{2} \backslash \mathrm{s}^{2}$ respectively. In case of HSB the peak value when the piston is near TDC i.e. $5^{0} \mathrm{bTDC}$. But in rest of the two bowls i.e. MHB and MHB with lip the raise in TKE starts in the early part of the compression stroke. The peak TKE in case of MHB is at $15^{\circ} \mathrm{bTDC}$ and for MHB the peak TKE occurs at $20^{\circ} \mathrm{bTDC}$. The peak values of TKE in HSB, MHB and MHB with lip are 88.45, 43.75 and $85.02 \mathrm{~m}^{2} \backslash \mathrm{s}^{2}$ respectively by considering SDRF.

\section{Effect of piston bowl configuration on NO emission:-}

Figure 4.11( $\left.\mathrm{a}_{1}\right), 4.11\left(\mathrm{a}_{2}\right)$ and 4.11( $\left.\mathrm{a}_{3}\right)$ gives the comparison of variation of NO emission with crank angle for the three bowl configurations. NO emission is maximum in HSB (0.01535\%) and minimum in case of MHB $(0.0124 \%)$. NO emission is case of MHB with lip is higher than MHB $(0.0136 \%)$. NO emission is maximum in HSB $(0.01522 \%)$ and minimum in case of MHB $(0.0123 \%)$ taking SDRF into account. NO emission with SDRF in case of MHB with lip is higher compared to MHB $(0.0131 \%)$.

\section{Effect of piston bowl configuration on HC emission:-}

Figure 4.12( $\left.\mathrm{a}_{1}\right), 4.12\left(\mathrm{a}_{2}\right)$ and 4.12( $\left.\mathrm{a}_{3}\right)$ gives the comparison of variation of $\mathrm{HC}$ emission with crank angle for the three piston bowl configurations. Predicted HC emission without SDRF in case of MHB with lip is minimum $(0.298 \%)$ and maximum in case of MHB $(0.363 \%)$. The HC emission in case of HSB is $(0.306 \%)$ slightly higher than MHB with lip. HC emission accounting SDRF is $0.295 \%, 0.355 \%$ and $0.299 \%$ for MHB with lip, MHB and HSB respectively. Hence, bowl with lip is found to be more optimum in view of $\mathrm{HC}$ emission.

\section{Effect of piston bowl configuration on $\mathrm{CO}$ emission:-}

Figure 4.13( $\left.\mathrm{a}_{1}\right), 4.13\left(\mathrm{a}_{2}\right)$ and 4.13( $\left.\mathrm{a}_{3}\right)$ gives the effect of piston bowl configuration on $\mathrm{CO}$ emission. It is noticed that the maximum $\mathrm{CO}$ emission is in $\mathrm{MHB}(0.335 \%$ without SDRF and $0.323 \%$ with SDRF) and the minimum CO emission is in case of HSB $(0.312 \%$ without SDRF and $0.308 \%$ with SDRF). The predicted CO emissions are maximum for MHB and minimum for HSB. MHB with lip falls between HSB and MHB (0.3125\% without SDRF and $0.309 \%$ with SDRF).

\section{Effect of piston bowl configuration on $\mathrm{CO}_{2}$ emission:-}

Figure 4.14( $\left.\mathrm{a}_{1}\right), 4.14\left(\mathrm{a}_{2}\right)$ and 4.14( $\left.\mathrm{a}_{3}\right)$ gives the effect of piston bowl configuration on emission of $\mathrm{CO}_{2}$. It is noticed that $\mathrm{CO}_{2}$ emission is same in case of HSB and MHB with lip (0.1723\% without SDRF and 0.1705\% with SDRF). It is lower in case of MHB $\left(0.1716 \%\right.$ without SDRF and $0.169 \%$ with SDRF). As it is mentioned earlier, $\mathrm{CO}_{2}$ formation is due to combustion of carbon in presence of oxygen, and higher $\mathrm{CO}_{2}$ concentration in the exhaust indicated better combustion. 


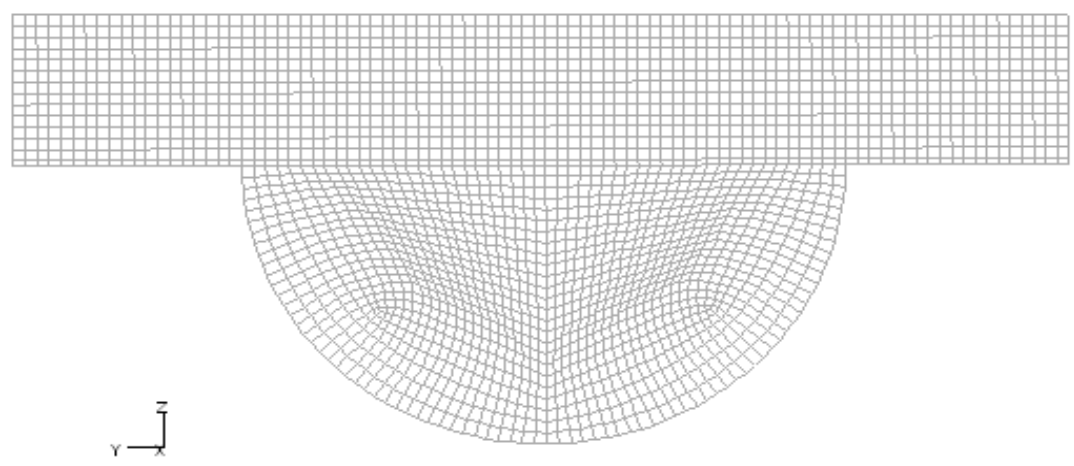

Gikl (Time-1.6667e-0Q)

Crank Angle-300.00(teg)

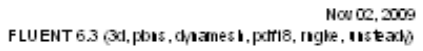

Fig 4.1 Computational mesh of hemispherical bowl

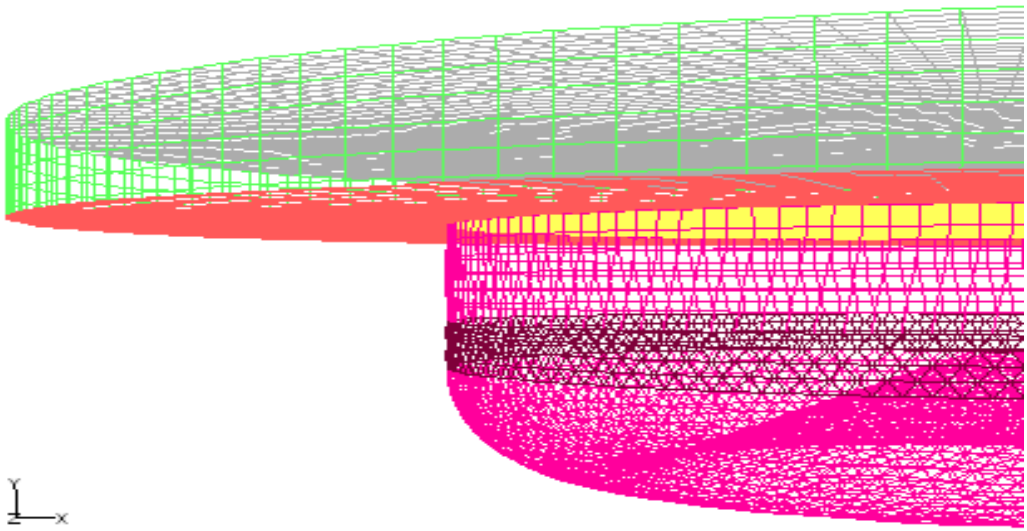

Fig 4.2 Views of the computational mesh (Mexican Hat bowl without lip)
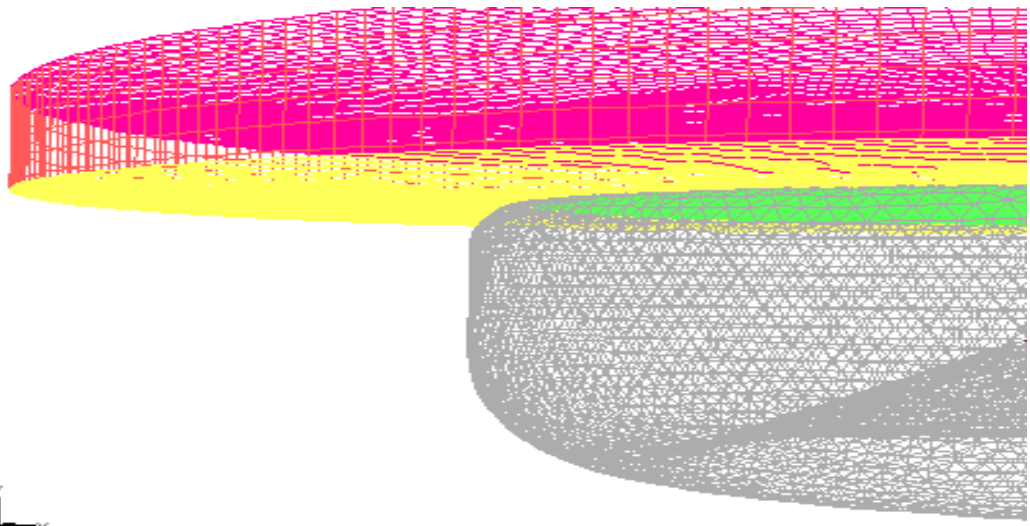

Fig 4.3 Views of the computational mesh (Mexican Hat bowl with lip) 


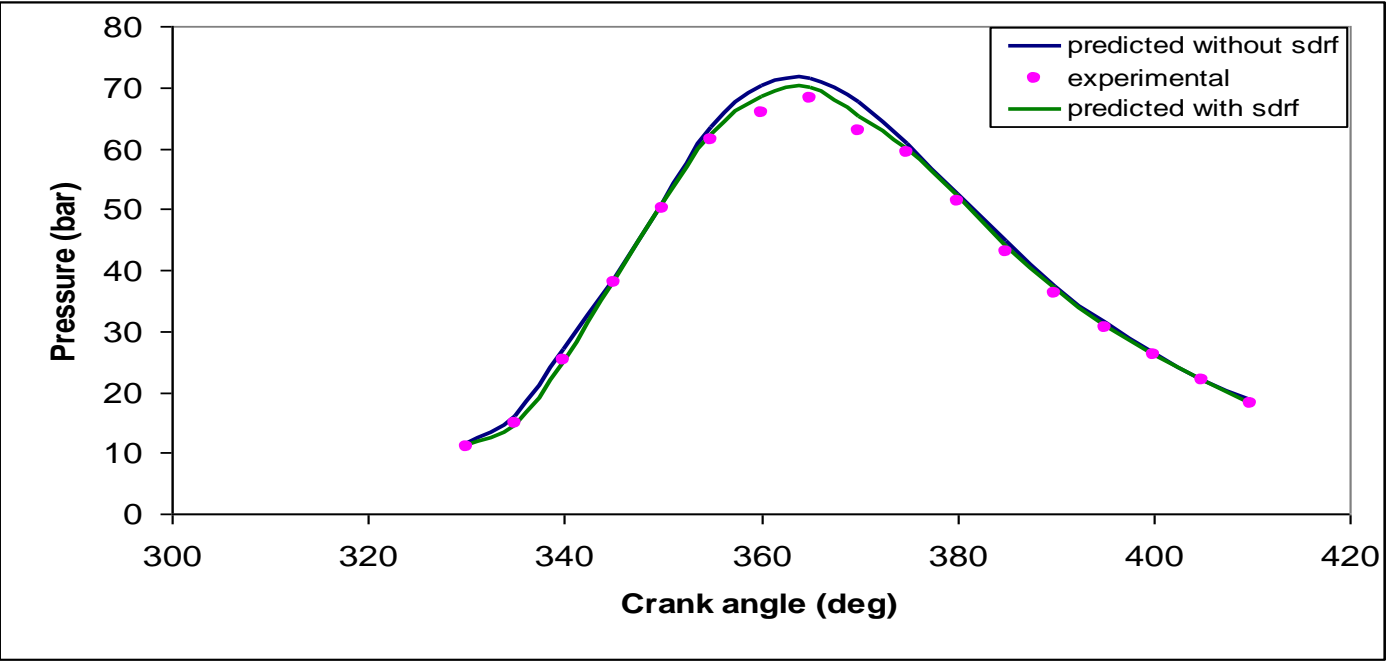

Fig 4.4: Variation of cylinder pressure with crank angle (spherical bowl).

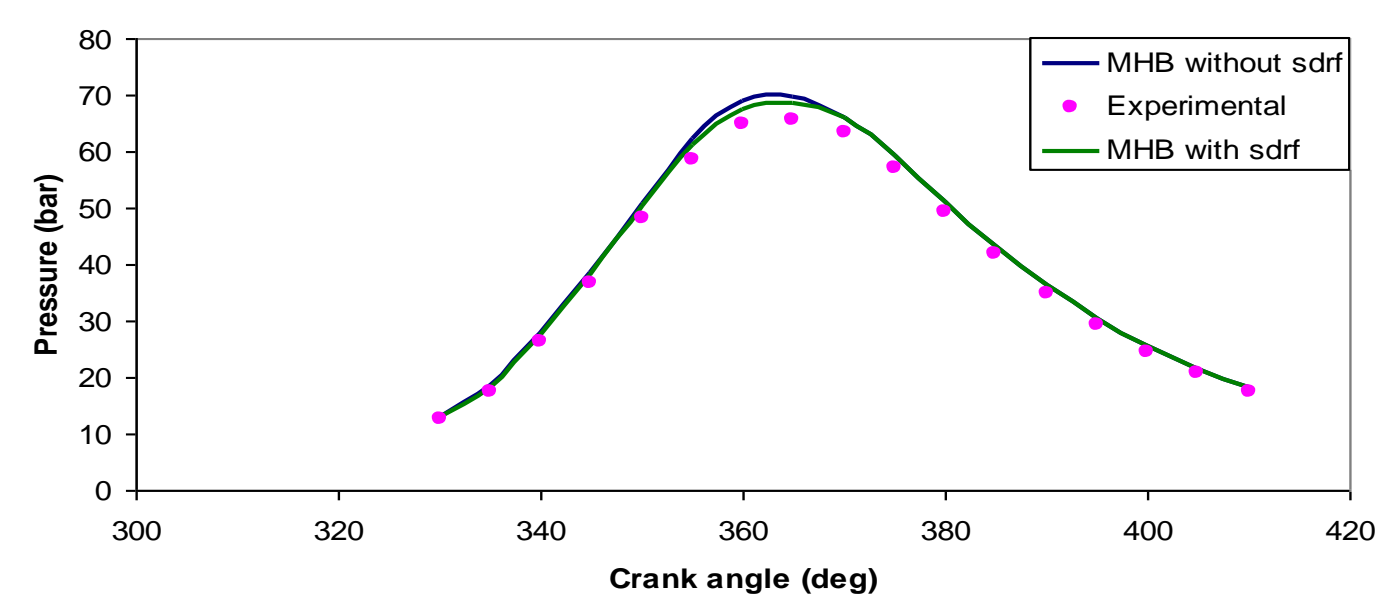

Fig 4.5: Variation of cylinder pressure with crank angle.

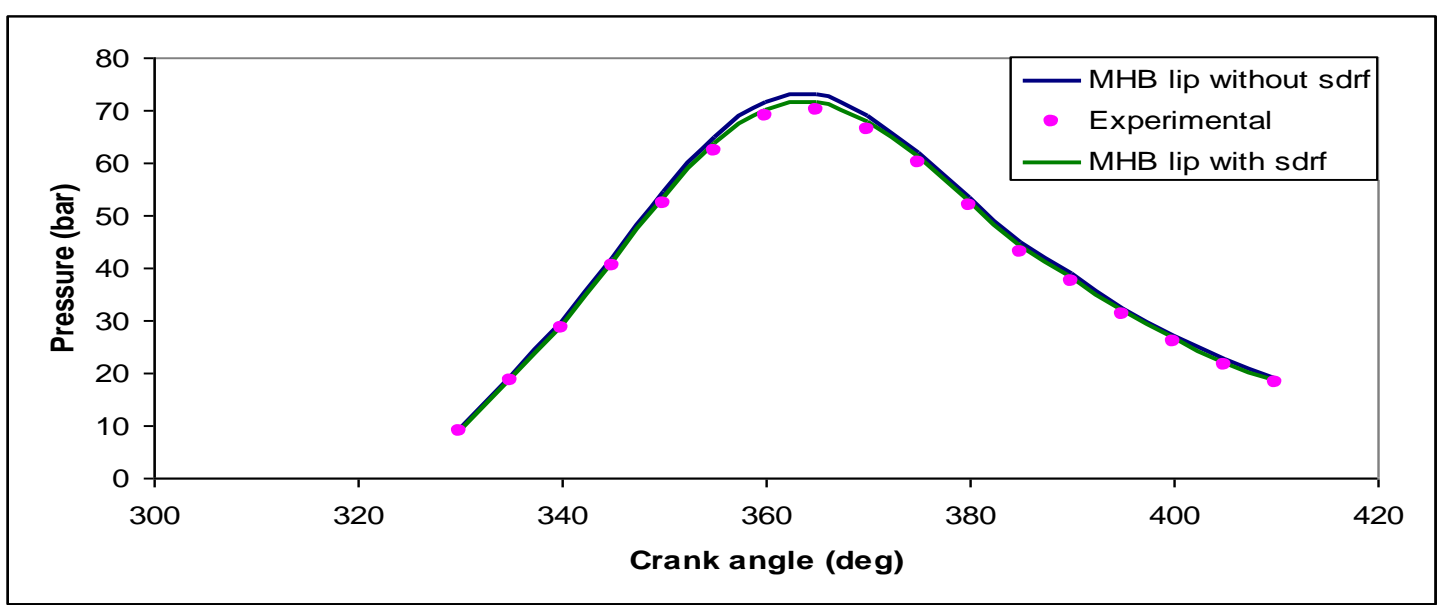

Fig 4.6: Variation of cylinder pressure with crank angle. 


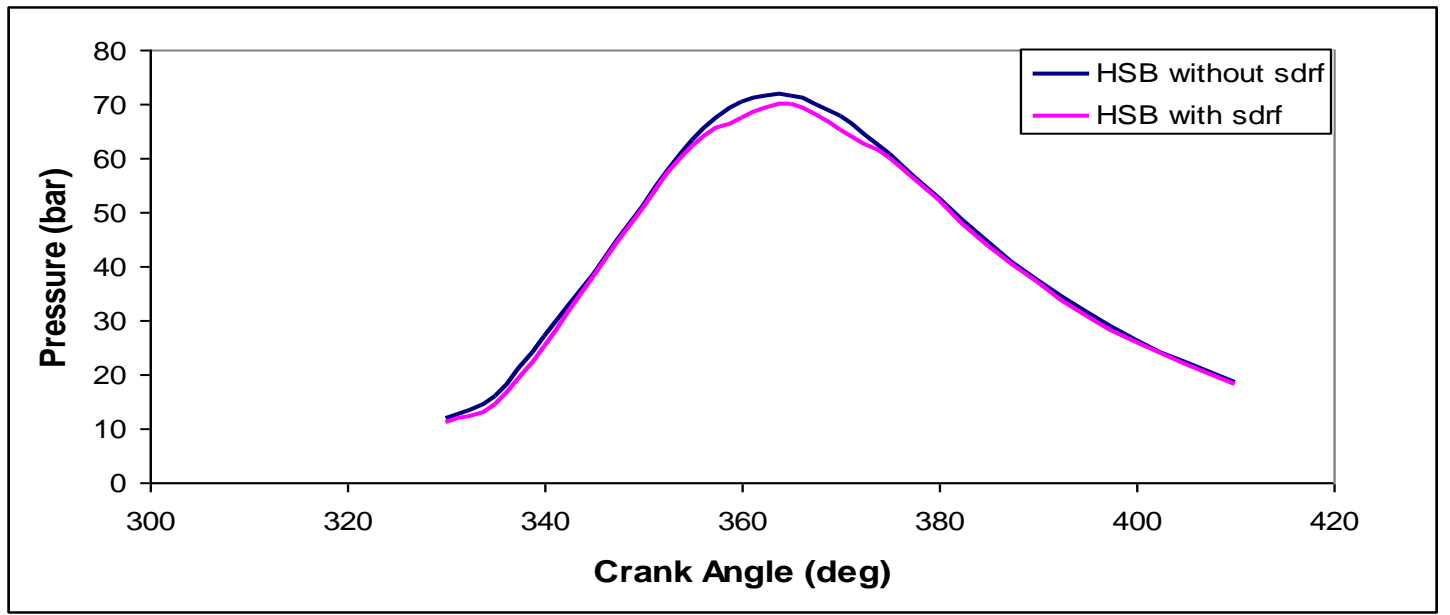

$\left(\mathrm{a}_{1}\right)$ Hemispherical bowl.

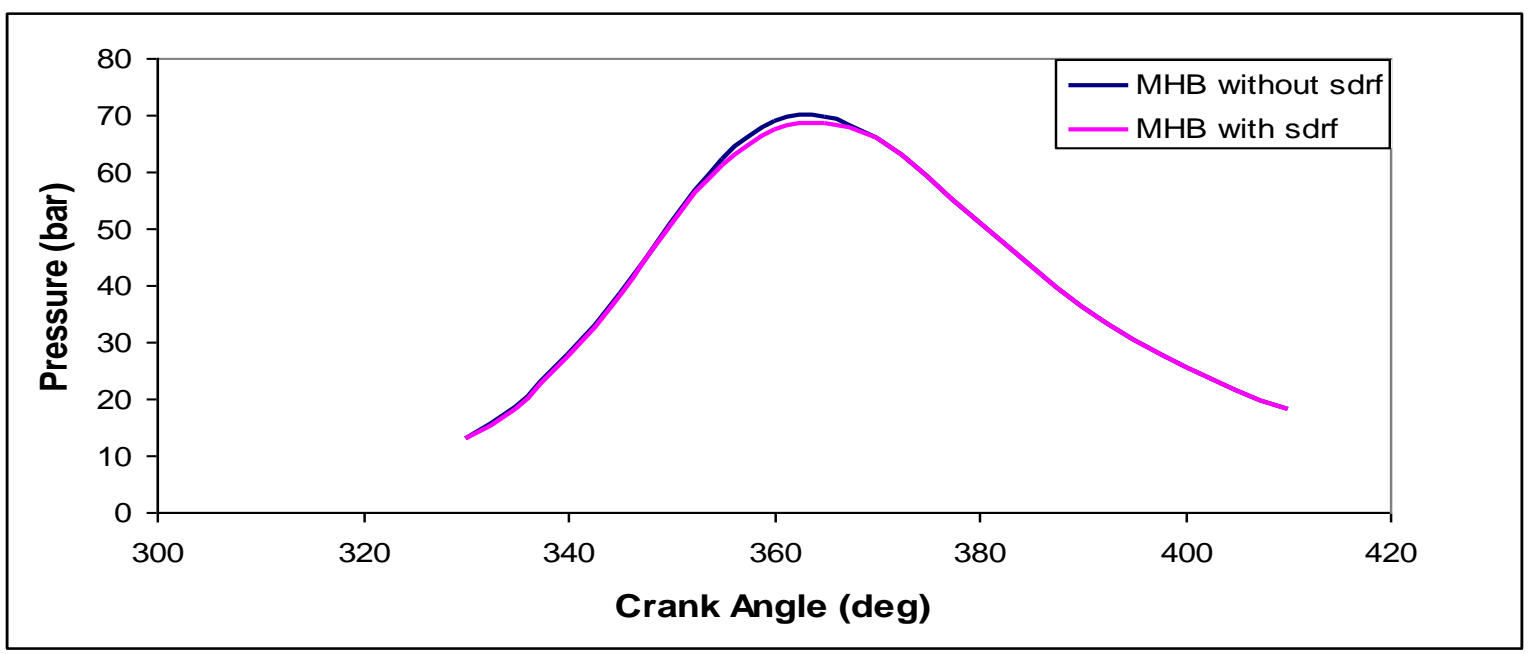

$\left(a_{2}\right)$ Mexican Hat bowl.

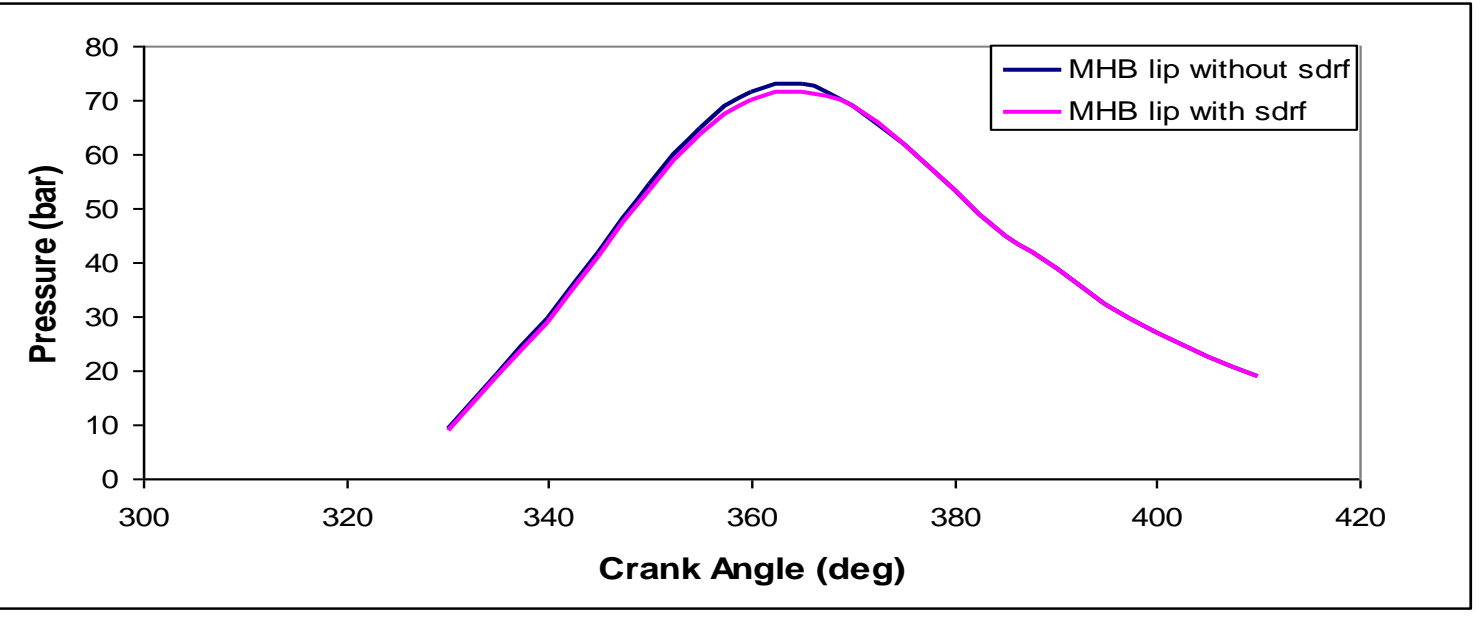

$\left(a_{3}\right)$ Mexican Hat Bowl with Lip.

Fig 4.7 Effect of piston bowl configuration on cylinder pressure. 


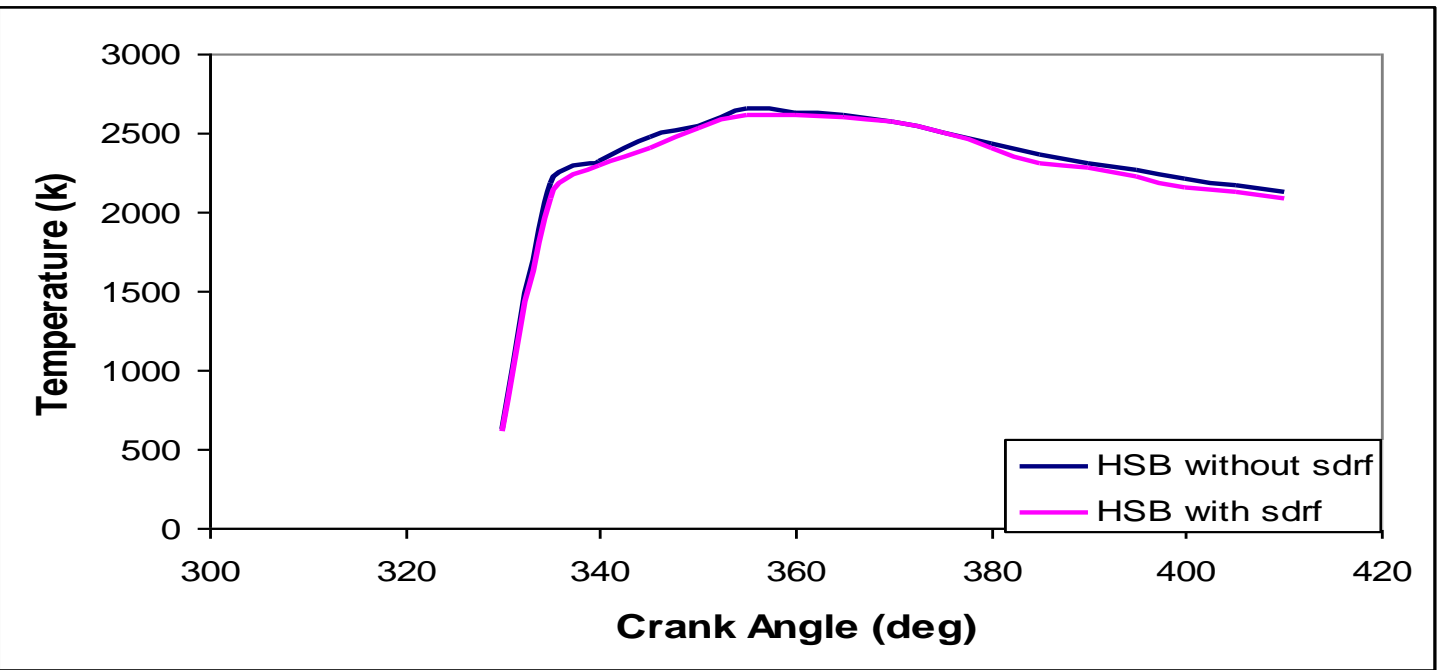

$\left(a_{1}\right)$ Hemispherical bowl.

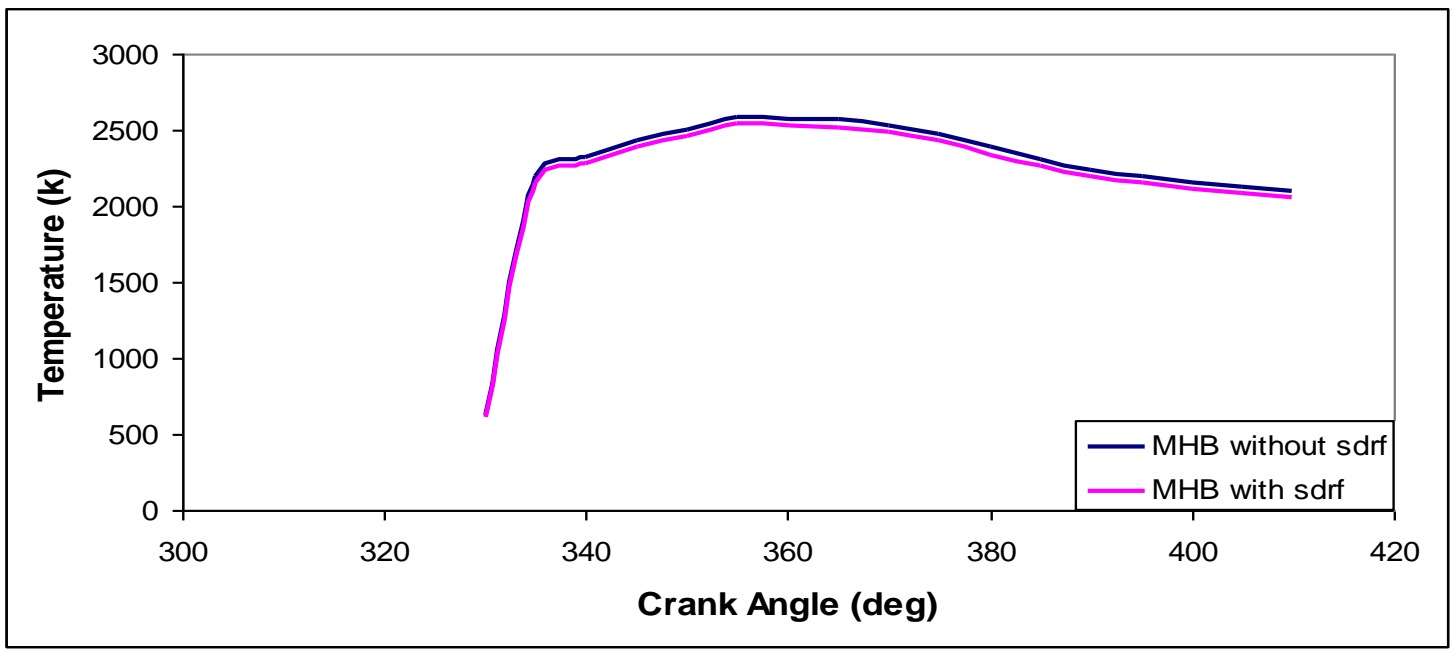

$\left(a_{2}\right)$ Mexican Hat bowl.

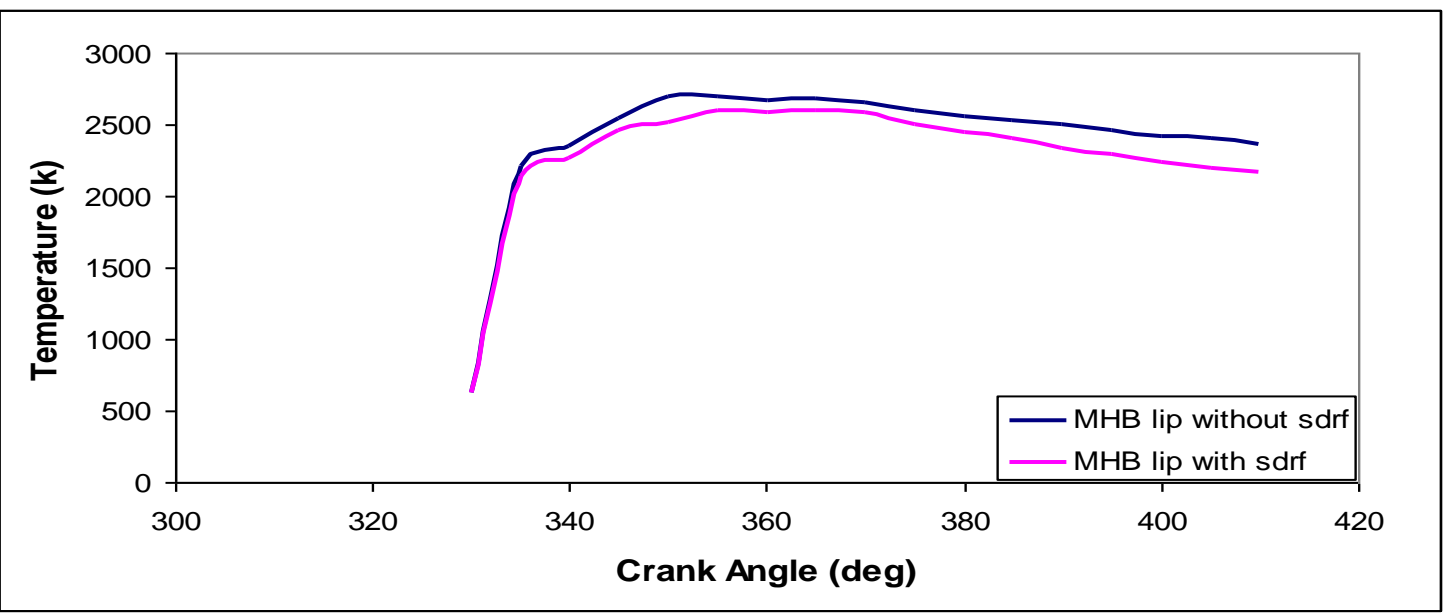

$\left(a_{3}\right)$ Mexican Hat Bowl with Lip.

Fig 4.8: Effect of piston bowl configuration on cylinder Temperature. 


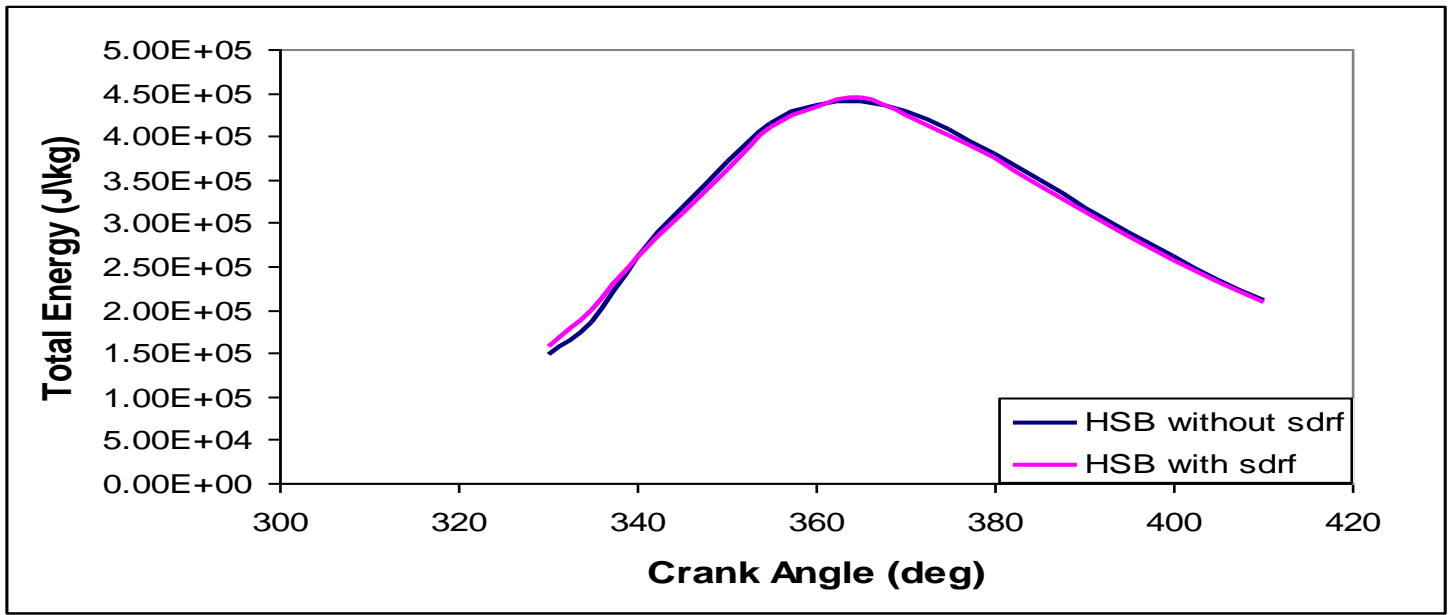

$\left(a_{1}\right)$ Hemispherical bowl.

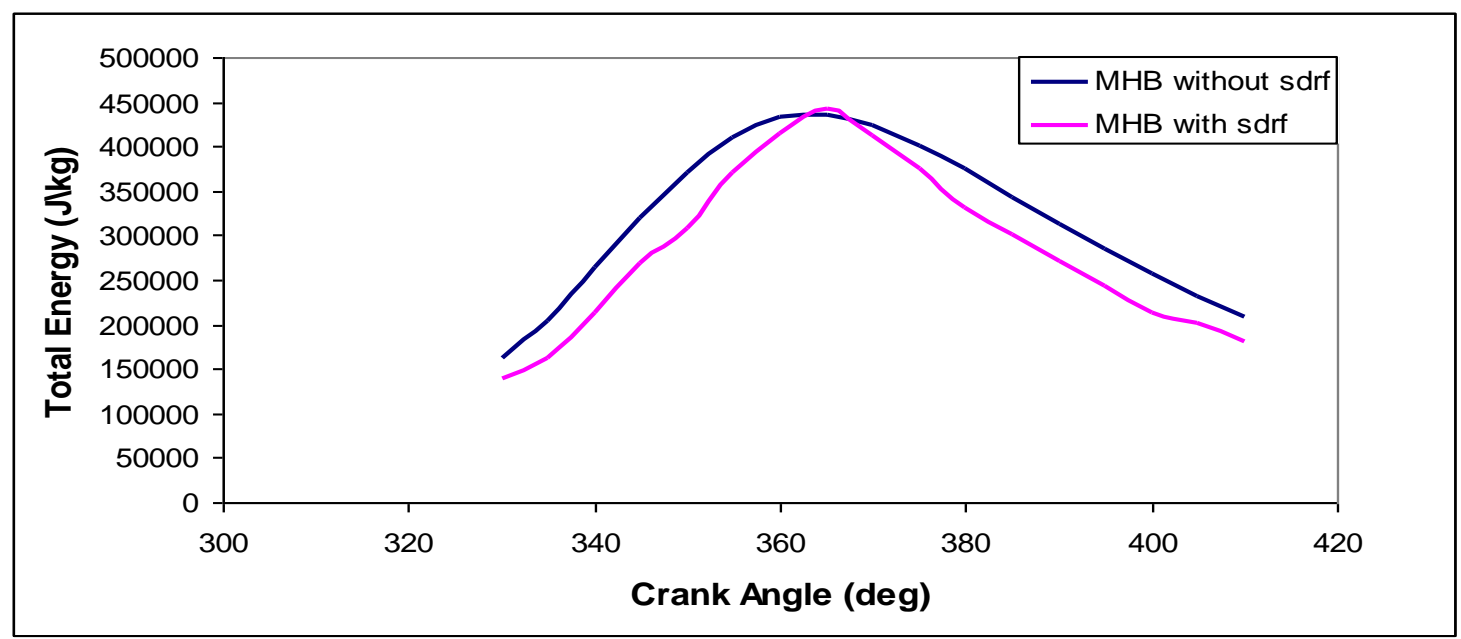

$\left(a_{2}\right)$ Mexican Hat bowl.

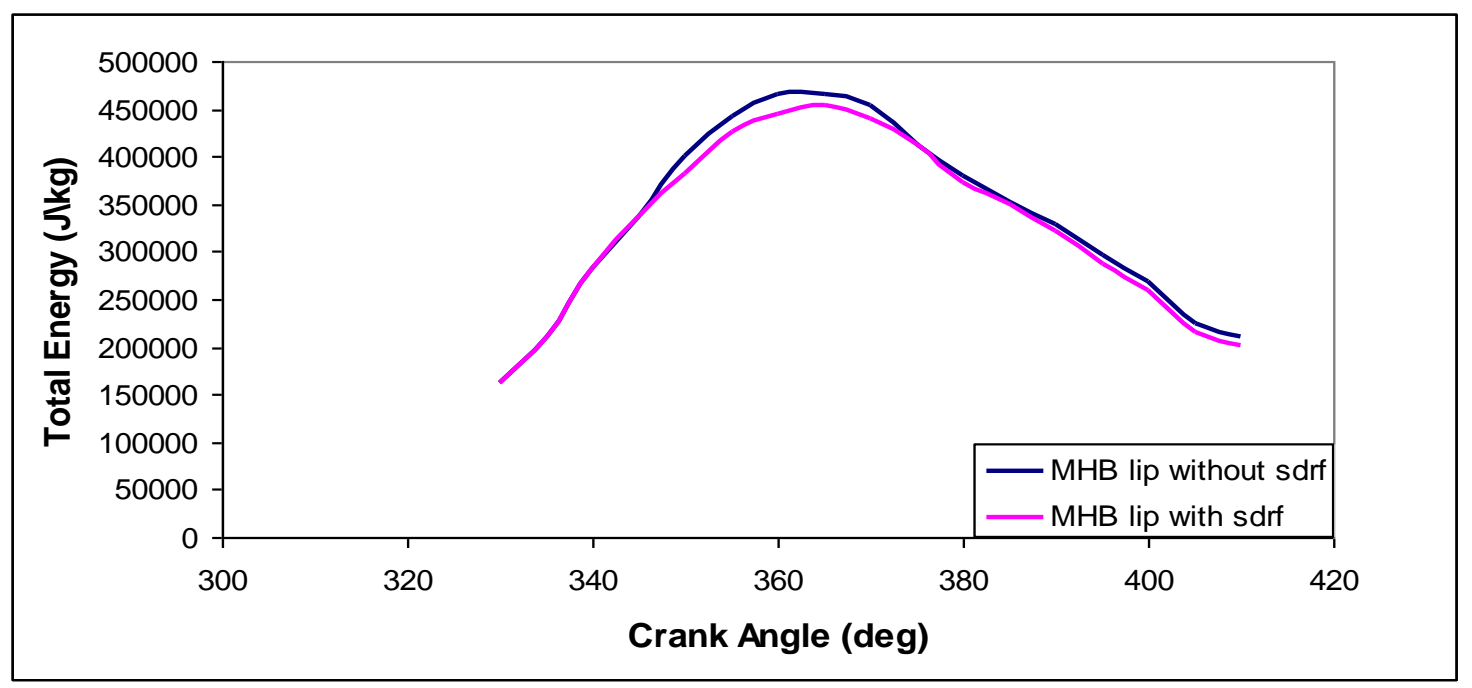

$\left(a_{3}\right)$ Mexican Hat Bowl with Lip.

Fig 4.9: Effect of piston bowl configuration on Total Energy. 


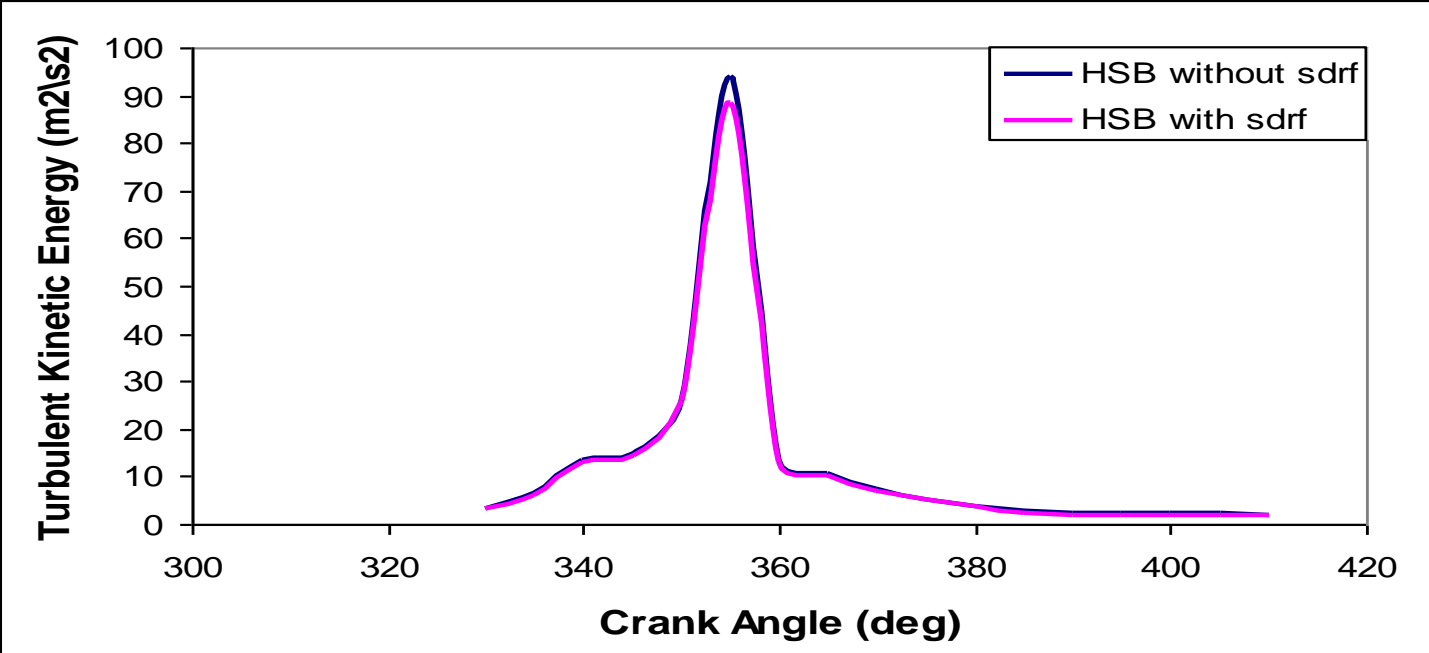

$\left(\mathrm{a}_{1}\right)$ Hemispherical bowl

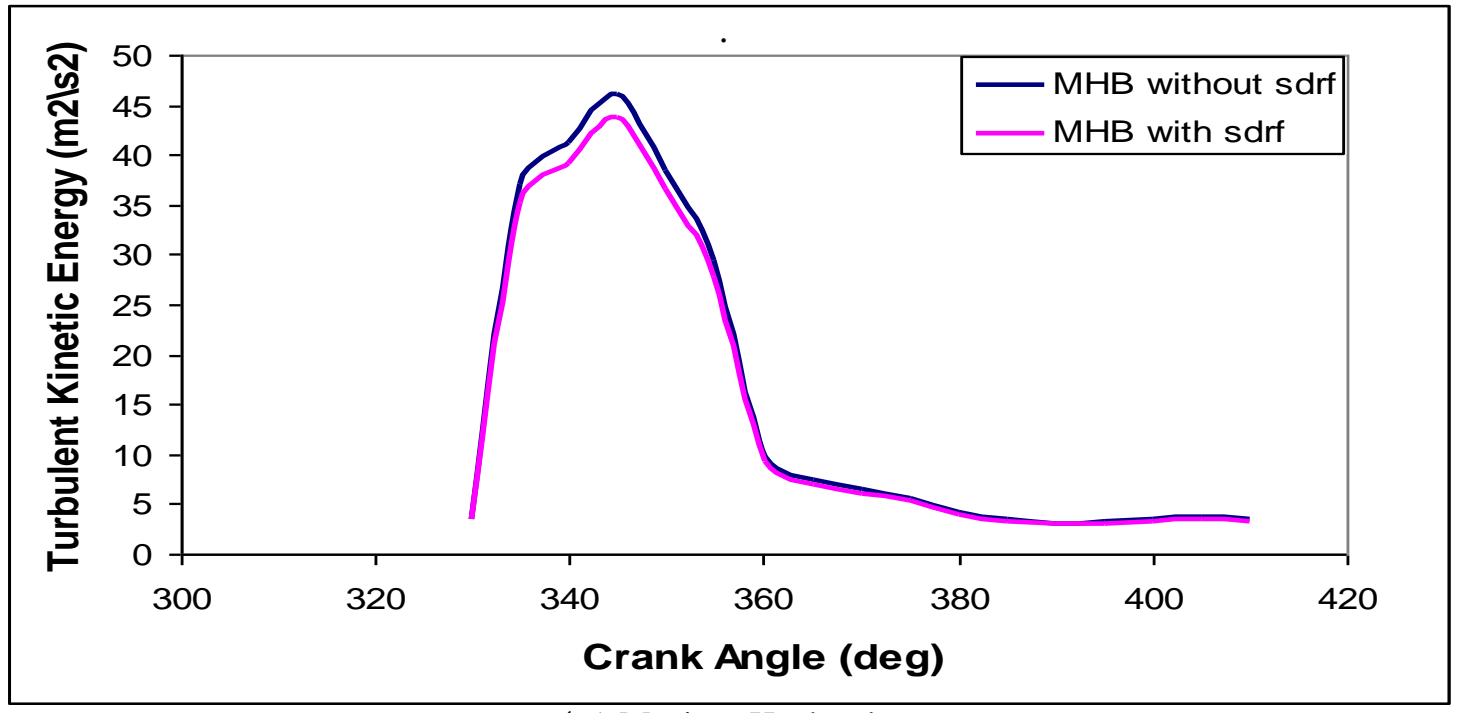

$\left(\mathrm{a}_{2}\right)$ Mexican Hat bowl.

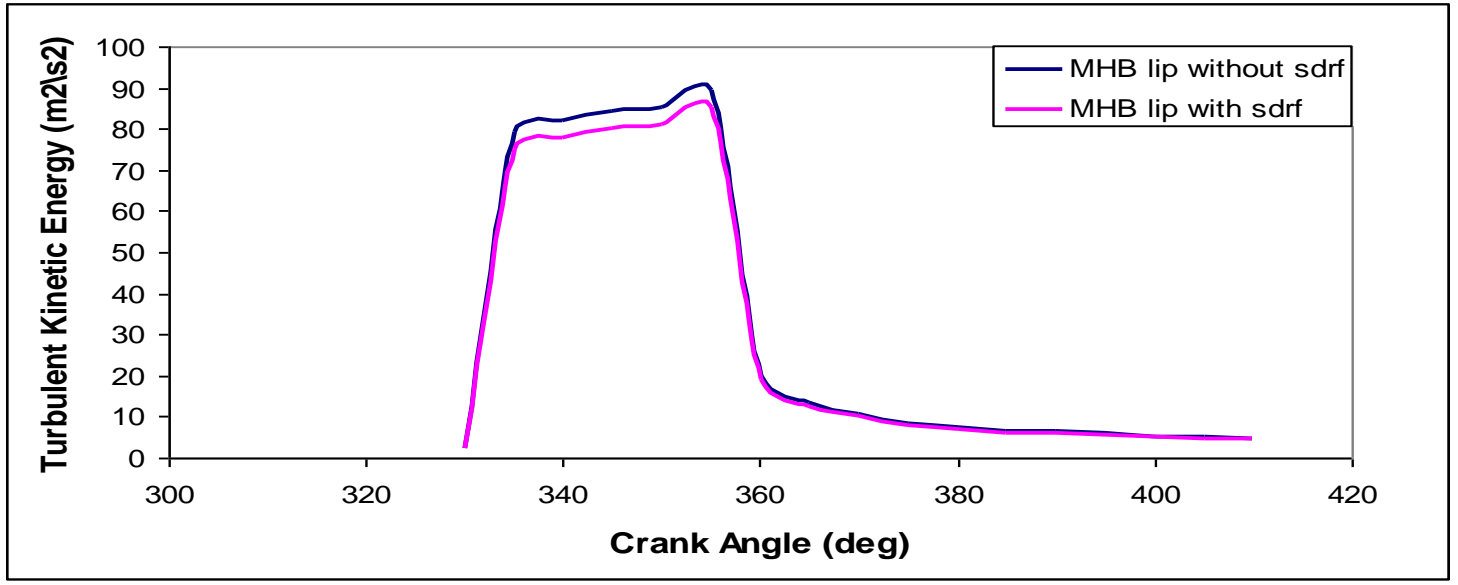

$\left(a_{3}\right)$ Mexican Hat Bowl with Lip.

Fig 4.10 Effect of piston bowl configuration on Turbulent Kinetic Energy. 


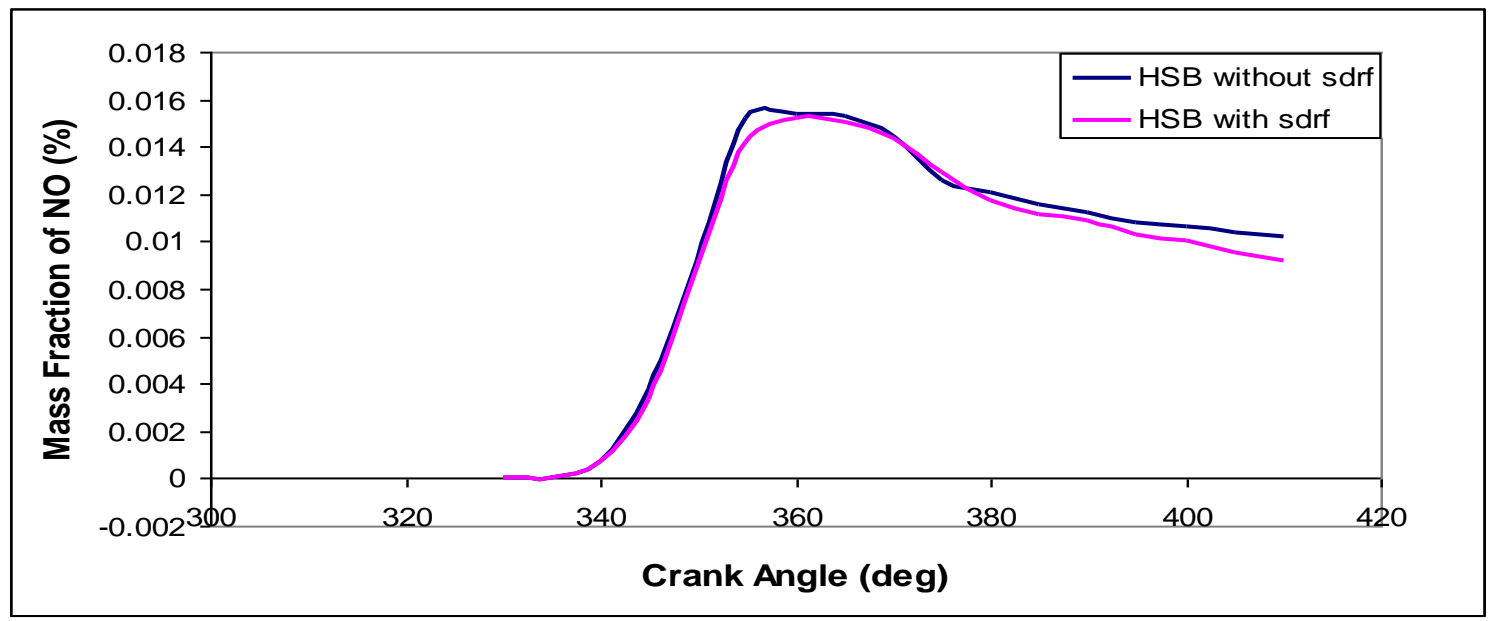

$\left(a_{1}\right)$ Hemispherical bowl

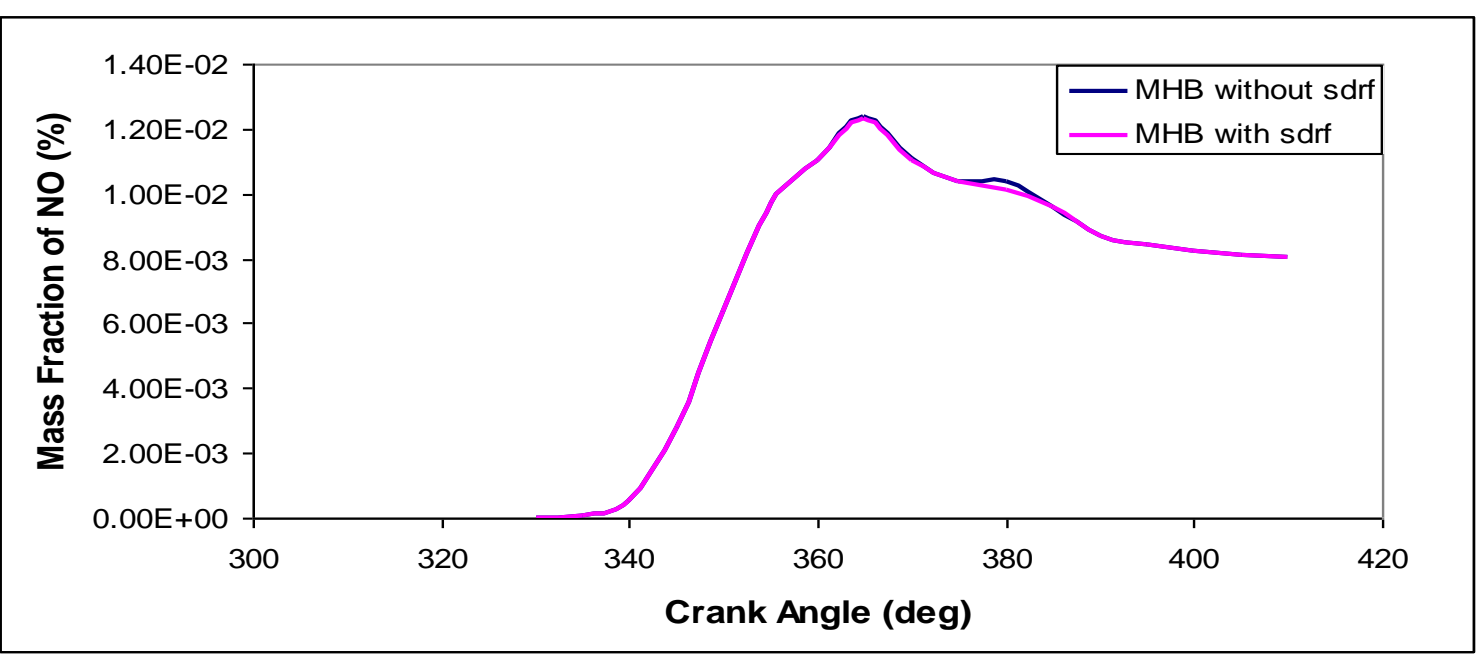

$\left(a_{2}\right)$ Mexican Hat bowl

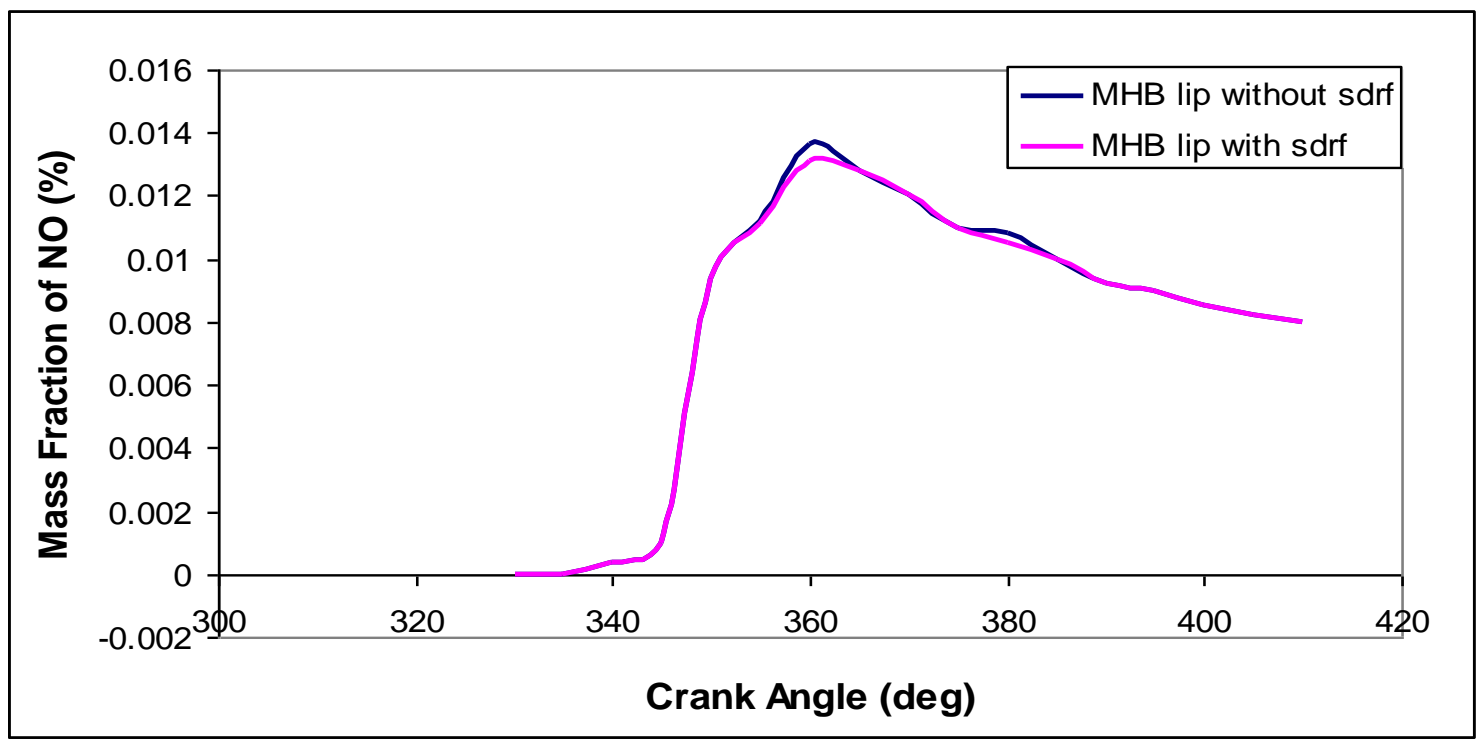

$\left(a_{3}\right)$ Mexican Hat Bowl with Lip.

Fig 4.11 Effect of piston bowl configuration on NO Emission. 


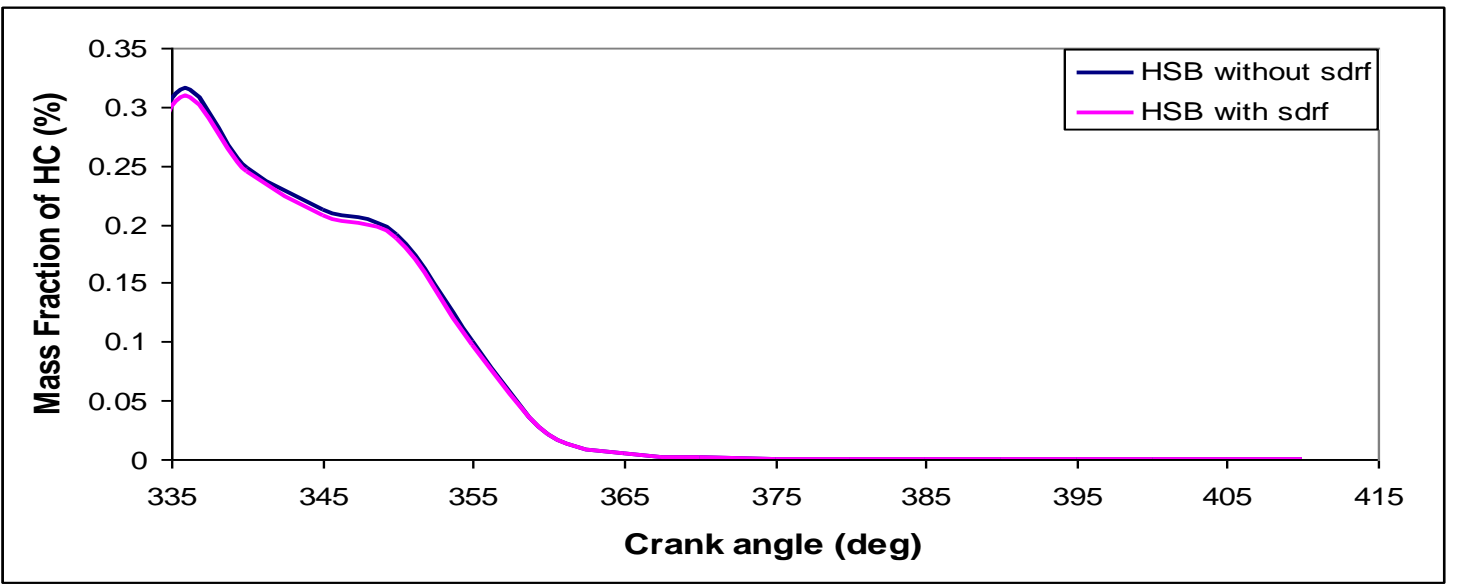

$\left(a_{1}\right)$ Hemispherical bowl.

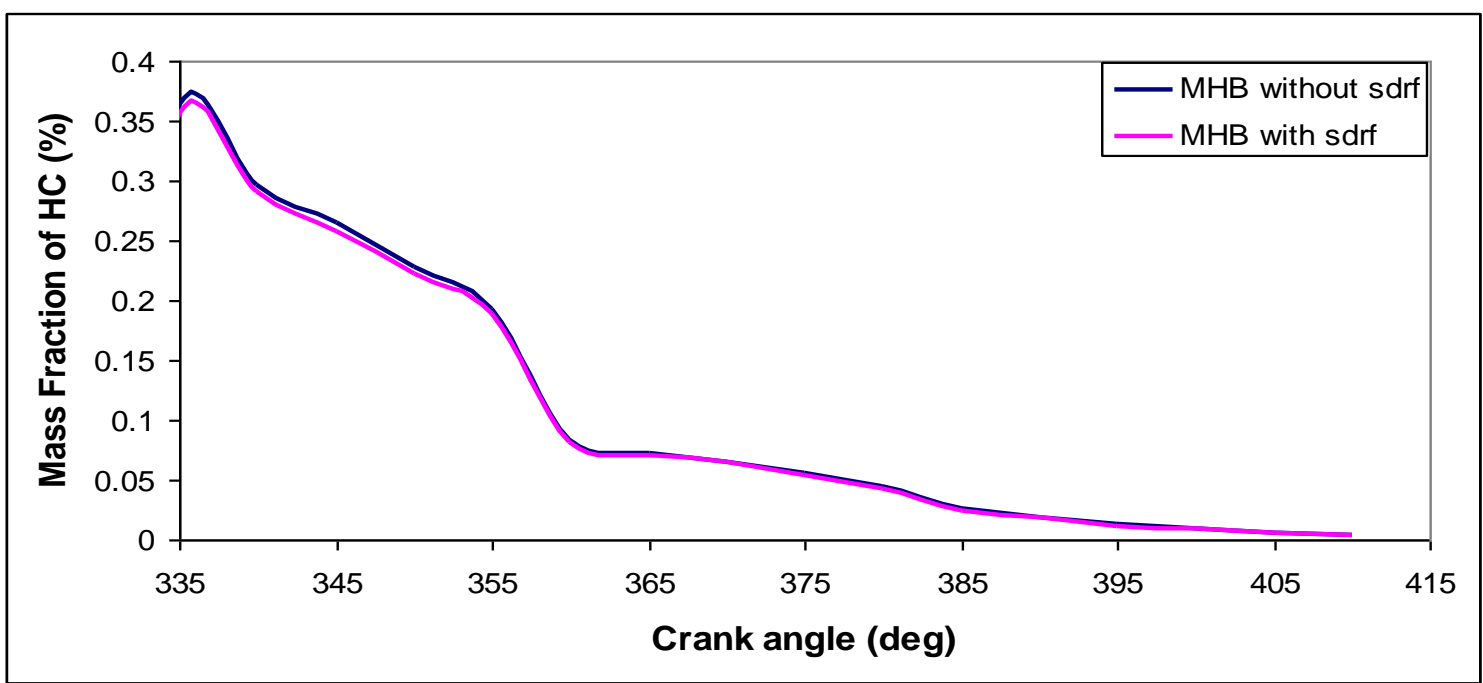

$\left(\mathrm{a}_{2}\right)$ Mexican Hat bowl.

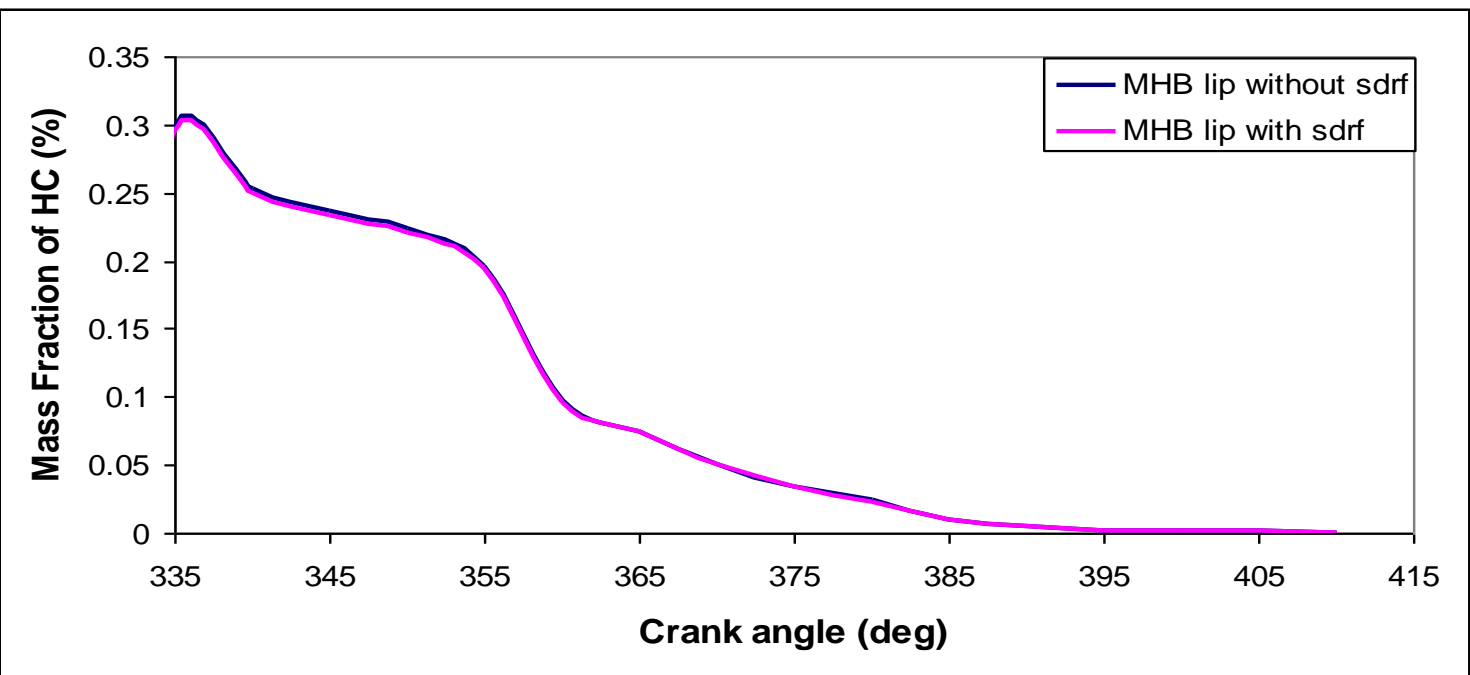

$\left(a_{3}\right)$ Mexican Hat Bowl with Lip.

Fig 4.12: Effect of piston bowl configuration on HC Emission. 


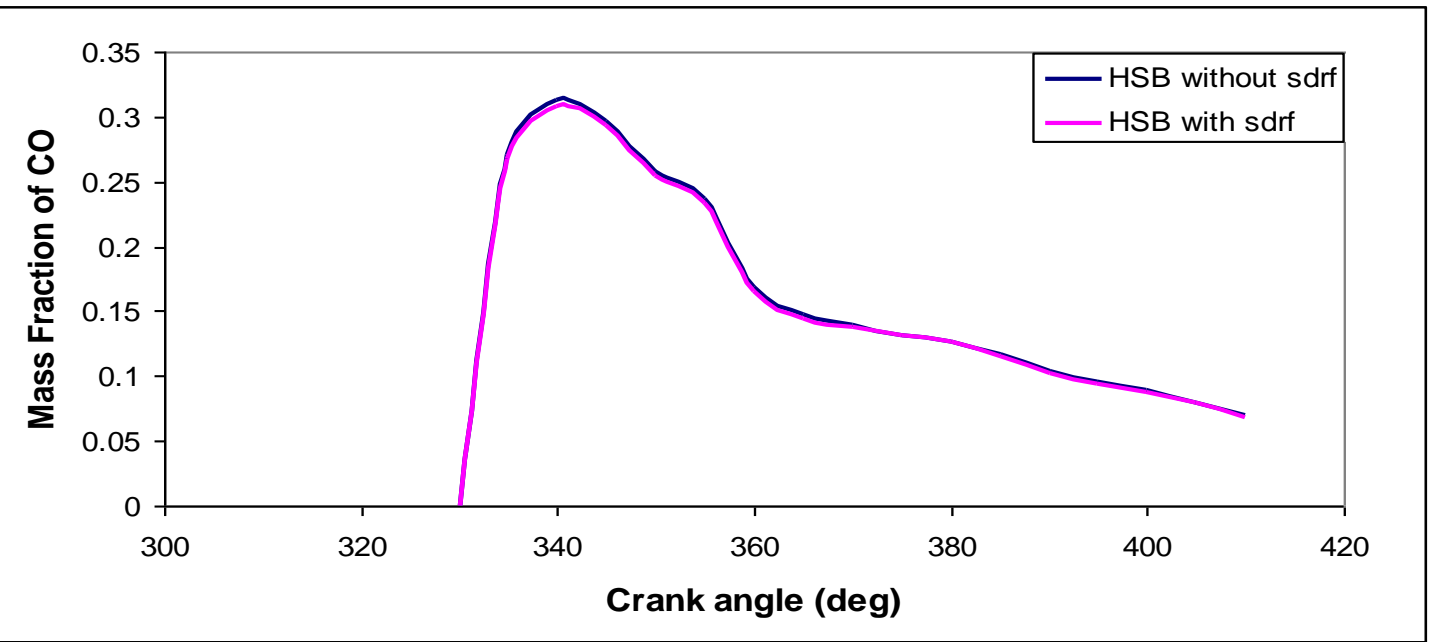

$\left(a_{1}\right)$ Hemispherical bowl.

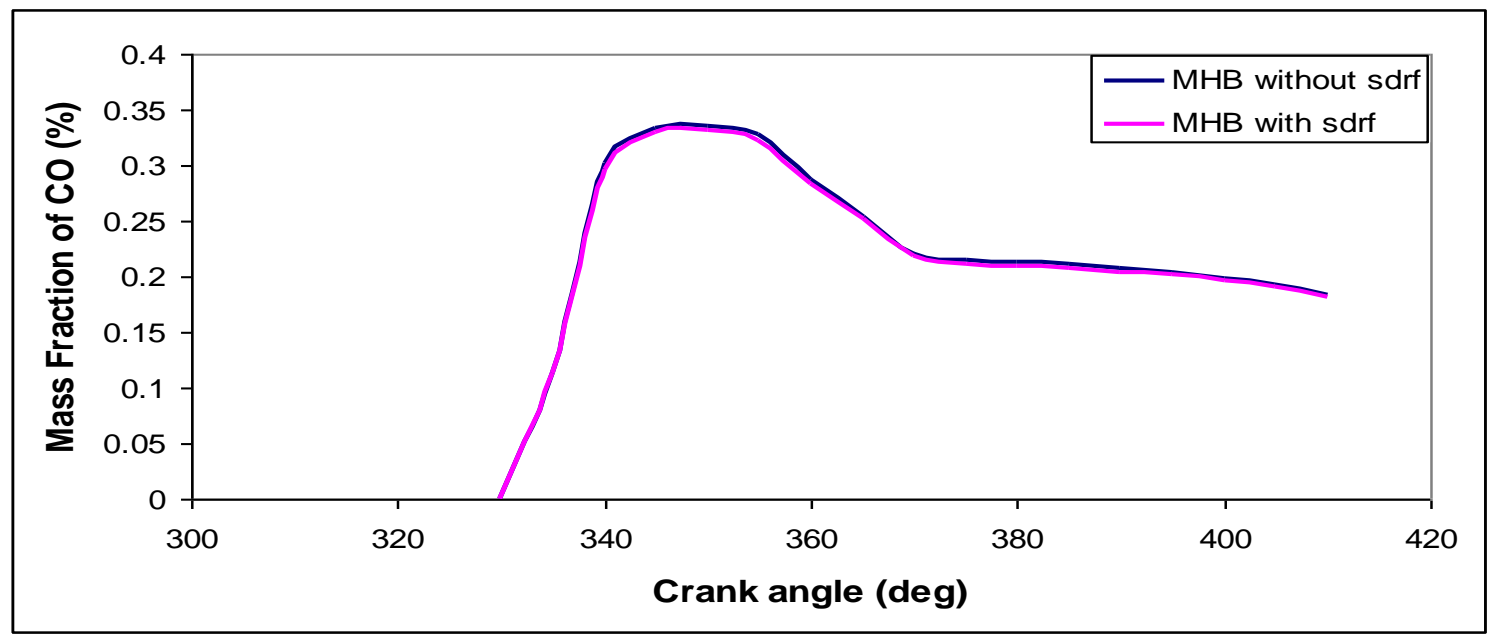

$\left(a_{2}\right)$ Mexican Hat bowl.

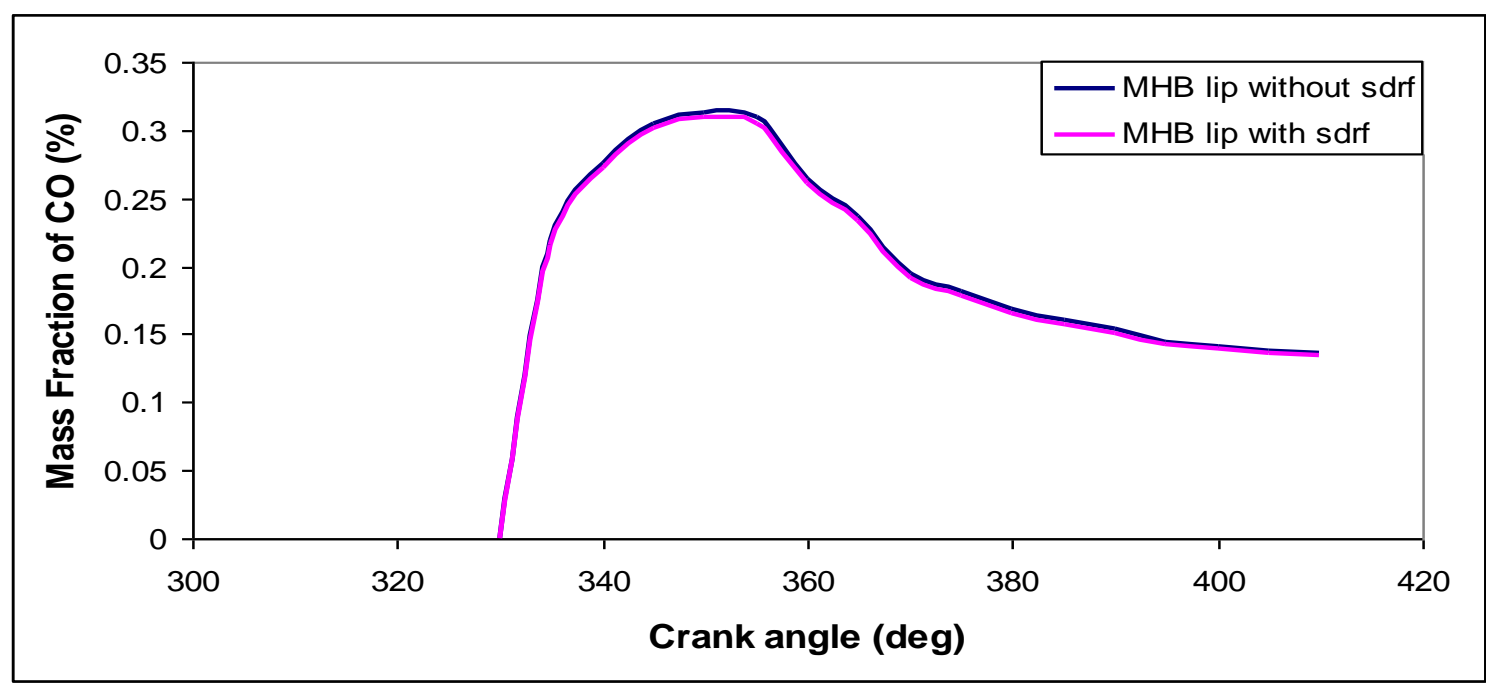

$\left(a_{3}\right)$ Mexican Hat Bowl with Lip.

Fig 4.13: Effect of piston bowl configuration on $\mathrm{CO}$ Emission. 


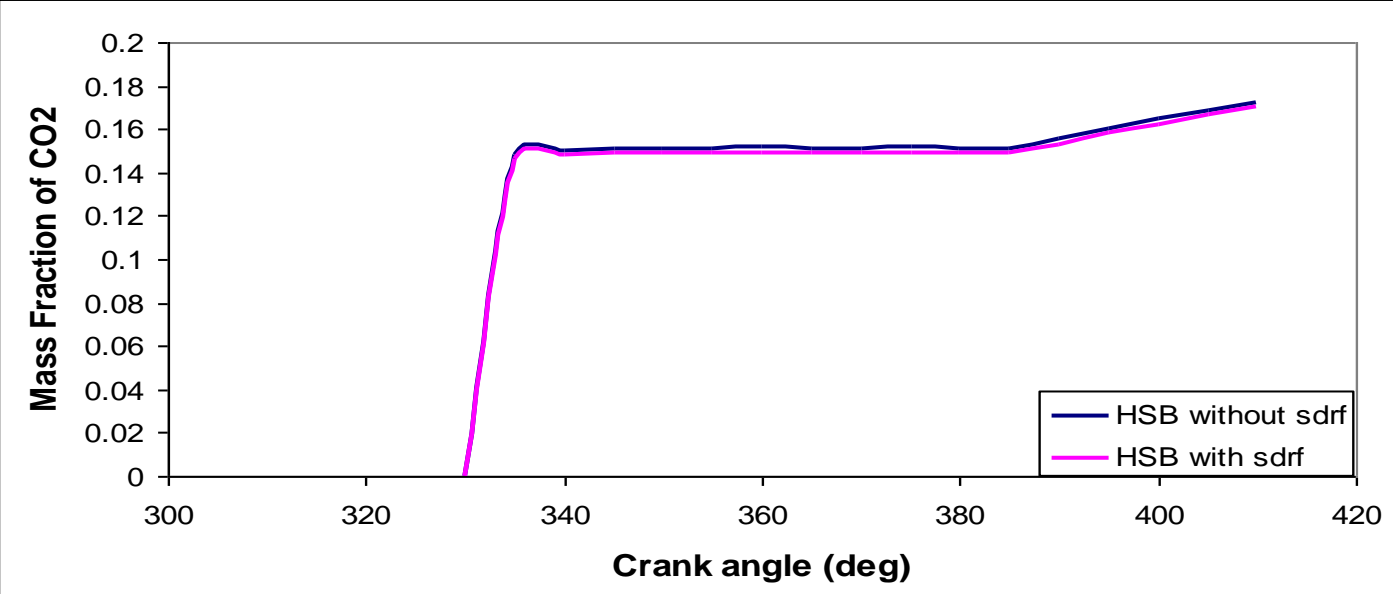

$\left(a_{1}\right)$ Hemispherical bowl.

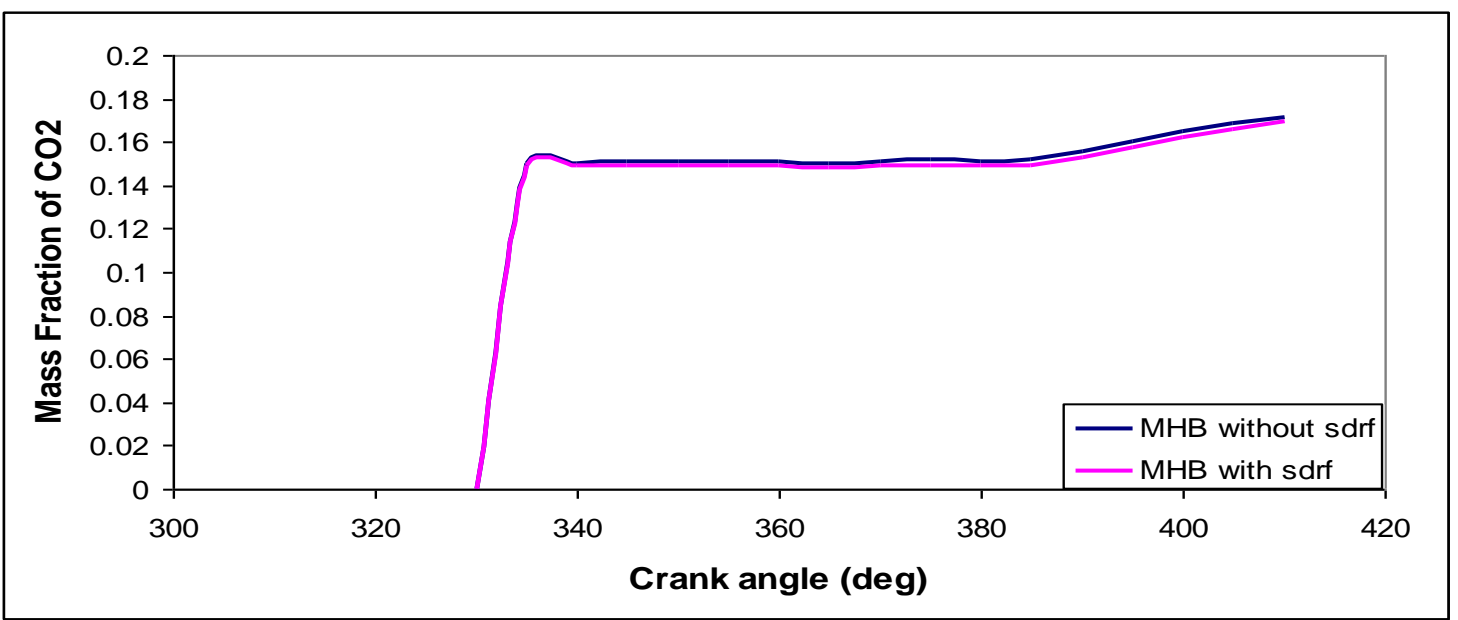

$\left(a_{2}\right)$ Mexican Hat bowl.

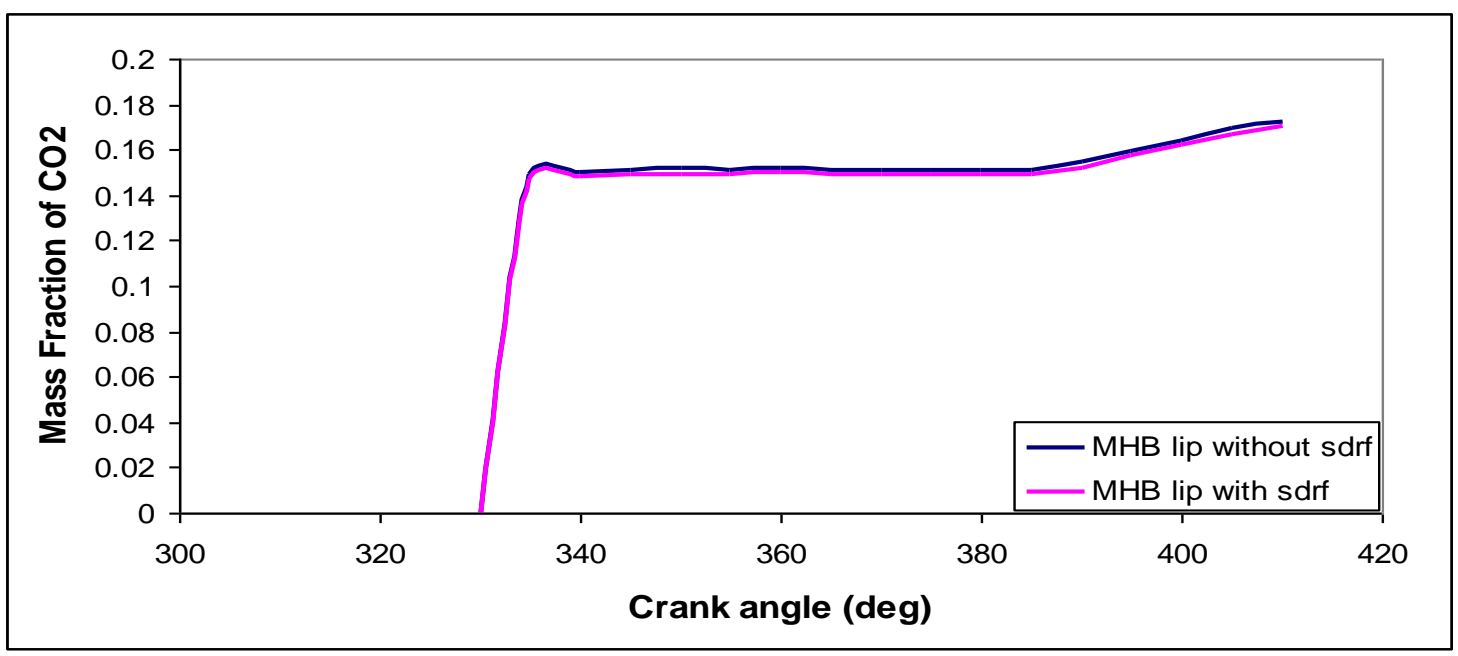

$\left(a_{3}\right)$ Mexican Hat Bowl with Lip.

Fig 4.14: Effect of piston bowl configuration on $\mathrm{CO}_{2}$ Emission. 


\section{Conclusions:-}

The present work is an attempt to improve the consistency of multidimensional code to predict the characteristics of in-cylinder flow and combustion. In the process FLUENT, a versatile fluid dynamic code with greater flexibility, is modified to account for SDRF and used in this work. The code is tested varying the parameters like piston bowl configuration. The important conclusions drawn are presented.

* The results are encouraging as very good agreement is noticed for the pressure histories reducing error percentage.

* For the tested bowl configurations the predicted and measured pressure histories have very good agreement compared to without SDRF. The error percentage in peak pressures is reduced from $4.449 \%$ to $2.58 \%$ for HSB $5.9 \%$ to $4 \%$ for MHB, $3.1 \%$ TO $1.83 \%$ for MHB with lip by accounting the effect of SDRF.

* The predicted peak pressures are higher than true values if SDRF is not accounted.

* HSB configuration is found optimum in view of pollution emissions. In this case CO, NO and $\mathrm{HC}$ are very much optimum.

\section{References:-}

1. B. John Heywood, Internal Combustion Engine Fundamentals, McGraw Hill International Editions, 1990.

2. Nobert Peters, Turbulent Combustion, Cambridge University Press, 2000.

3. D. John Anderson Jr, Computational Fluid Dynamics - The Basics with applications, Mc Graw-Hill International Edition, 1995.

4. S. Gold Stein, Modern Developments in Fluid Dynamics, Vol.2, p. 331, Oxford University Press, NY, 1938.

5. K. Hanjalic, Two Dimensional Flow in a Axisymmetric Channels, Ph.D Theses, university of London, 1970.

6. F.H. Harlow and P.I. Nakayama, Transport of Turbulence Energy Decay Rate, Los Almos Sci Lab,University of California, Report LA-3854, 1968.

7. F. Payri, J Benejas, X Margot, A Gil, "CFD modelling of the in-cylinder flow in direct injection diesel engine". Elsevier, September 2003.

8. J S Kim and S R Lee, "Diffusional - thermal instability in strained diffusion flames with unequal Lewis numbers", Combustion Theory modelling 31999.

9. K. Rajagopal, Three dimensional Modeling of In-Cylinder Flows, Fuel-Air Mixing and Combustion in a Four Stroke Compression Ignition Engine, Ph.D Theses, IIT Madras, March 1991.

10. FLUENT Users Manual, FLUENT 6.3 documentation, FLUENT International Corporation Limited, USA. 